\title{
Which pavement structures are best suited to limiting the UHI effect? A laboratory-scale study of Parisian pavement structures
}

\author{
Martin HENDEL ${ }^{1,2^{*}}$, Sophie PARISON ${ }^{1,3}$, Arnaud GRADOS ${ }^{4}$, Laurent ROYON ${ }^{1}$ \\ ${ }^{1}$ Univ Paris Diderot, Sorbonne Paris Cité, LIED, UMR 8236, CNRS, F-75013, Paris, France \\ ${ }^{2}$ Université Paris-Est, ESIEE Paris, département SEN, F-93162 Noisy-le-Grand, France \\ 3Paris City Hall, Water and Sanitation \& Road and Transportation Departments, F-75013, Paris, France \\ ${ }^{4}$ Univ Paris Diderot, Sorbonne Paris Cité, MSC, UMR 7057, CNRS, F-75013, Paris, France \\ *corresponding author: martin.hendel@,univ-paris-diderot.fr
}

\begin{abstract}
Paving materials can negatively impact the urban climate, but knowledge of the thermal and climatic behavior of multilayer urban structures is lacking, particularly under heat-wave conditions. To this aim, a laboratory-scale experiment was developed to characterize pavement samples under heat-wave conditions. Surface albedo and evapotranspiration are confirmed as the dominant parameters for surface heating. The thermal properties of the underlying layers of pavement structures also impact their behavior and contribution to the urban climate. In particular, the combination of high effusivity and diffusivity of the granite sidewalk structure allow it to exhibit "cool" behavior during the day and "hot" behavior at night despite its relatively high albedo. A solar transmission index is proposed, including both the radiative and the thermal properties of a structure's constitutive layers, to rank structures by their ability to transmit absorbed radiation in depth.

Future work with the developed experimental platform will aim to evaluate the performance and optimize the watering method of pavement-watering for different kinds of pavement structures.
\end{abstract}

Keywords: urban heat island; urban paving materials; thermal properties; heat waves

\section{Nomenclature}

$\alpha$

AHI

$c_{p}$

E

$\varepsilon$

$k$

b

$H$

I

IR

l

L

$\lambda$ albedo [-]

atmospheric heating index

specific heat $[/(\mathrm{kg} . \mathrm{K})]$

evaporation rate $[\mathrm{g} / \mathrm{s}]$

emissivity [-]

effective thermal conductivity

[W/(m.K)]

convective heat transfer

coefficient [W/ $\left.\left(\mathrm{m}^{2} \cdot \mathrm{K}\right)\right]$

upwards sensible convective flux $\left[\mathrm{W} / \mathrm{m}^{2}\right]$

spectral irradiance $\left[\mathrm{W} /\left(\mathrm{m}^{2} . \mathrm{nm}\right)\right]$

infrared

vaporization latent heat of water: $2,260 \mathrm{~J} / \mathrm{kg}$

incident longwave radiation [W/ $\left./ \mathrm{m}^{2}\right]$

wavelength [nm]
LW

$\Phi_{g}$

$\Phi_{\text {rad }}$

$r$

$R_{n}$

S

$\sigma$

SW

$\tau$

$T_{\text {air }}$

$T_{z}$

TSR

UHI longwave

global surface heat flow $\left[\mathrm{W} / \mathrm{m}^{2}\right]$

radiative surface heat flow

$\left[\mathrm{W} / \mathrm{m}^{2}\right]$

spectral reflectivity [-]

downwards net radiation

$\left[\mathrm{W} / \mathrm{m}^{2}\right]$

incident shortwave radiation

$\left[\mathrm{W} / \mathrm{m}^{2}\right]$

Stefan-Boltzmann constant $\left[\mathrm{W} /\left(\mathrm{m}^{2} \cdot \mathrm{K}^{4}\right)\right]$

shortwave

solar transmission index [-]

air temperature $\left[{ }^{\circ} \mathrm{C}\right]$

pavement temperature at depth

z.

total solar reflectance

Urban Heat Island 


$\begin{array}{llll}V_{z} & \text { downwards conductive heat flux } & \varepsilon & \text { emissivity }[-] \\ \text { at depth } ₹\left[\mathrm{~W} / \mathrm{m}^{2}\right] & \mathrm{n} & \text { layer } \mathrm{n} \\ \text { Subscript/superscript } & \mathrm{ref} / \mathrm{up} & \text { reflected or upwards } \\ \alpha \quad \text { albedo }[-] & z & \text { depth }[\mathrm{m}]\end{array}$

\section{Introduction}

Materials used in urban environments have strong impacts on urban climates and consequently on pedestrian thermal comfort. Depending on their properties, they contribute more or less to the urban heat island (UHI) effect [1], [2]. Several UHI countermeasures involving cool materials, urban greening or urban watering have been studied to address these issues with the goal of limiting the health, energy and other effects of UHI [3]-[7].

Previous work by the authors has focused on the field study of pavement-watering as a climate change adaptation measure for Paris against increasing and intensifying heat waves. Field testing conducted every summer since 2013 has helped determine the cooling effects and water consumption of the method under heat-wave conditions [8]-[11]. These analyses have underlined the important role played by the materials being watered on cooling performance. Indeed, while a given watering frequency may be valid for asphalt road surfaces, they are unlikely to be valid for other materials with different water-holding capacities, albedo or other relevant properties. Given the wide variety of materials used in cities, it is important for decisionmakers to be able to account for this when designing a city-wide pavement-watering strategy, with field trials being expensive and impractical for this purpose. Smaller-scale work is therefore required to account for this limitation.

To date, experimental work on urban paving materials has principally focused on their surface layers, without taking the influence of the underlying layers into account, with few exceptions [12]. Most work is conducted outdoors and requires large surfaces to compare different materials simultaneously under identical weather conditions [1], [13], [14], while other studies provide detailed analyses of the heat budgets of pavement materials [12], [15], [16]. These studies often have limited instrumentation, at best only temperature at two or three different depths.

A handful of studies are conducted in the lab and include a radiation source with a heat-up and cool-down period, i.e. day and night phases [17], [18]. The radiation source is an infrared lamp in both studies, neither of which control other climate conditions, e.g. air temperature or humidity, though wind speed is controlled in one study [18]. Similarly, only single material layers up to $14 \mathrm{~cm}$ thick are considered and climate cycles are less than 24 hours long. In some cases, measurement strategies use temperature a few centimeters deep as a proxy for surface temperature, a vital indicator of the climatic behavior of the materials under study. However, better understanding of the thermal and climatic behavior of paving materials remains necessary to assist decision-makers and urban designers.

This paper presents a lab experiment used to characterize the thermal behavior of Parisian street materials under heat-wave conditions. Temperature and heat flow measurements conducted at different depths on samples of five Parisian pavement structures are used to study and compare their thermal behavior. Their contribution to the urban climate is also evaluated and discussed. Lab findings are validated against field observations for the asphalt road structure.

\section{Materials and Methods}

Five Parisian pavement structures are studied in the lab under heat-wave-like conditions and their behavior is compared between them. First, we present the composition and instrumentation of the pavement samples. Next, the experimental setup and protocol used for this purpose is described. Third, the surface heat balance of the pavement structures and the analyses that are conducted on this basis are presented. Finally, an indicator of convective heat exchange from the pavement to the atmosphere is formulated.

\section{Pavement samples}

The thermal behaviour of five different Parisian street structures is compared in the lab: standard asphalt road and sidewalk structures as well as samples of cement-stabilized sand, granite-paver sidewalk and lawn structures. Figure 1 describes the composition of the samples constructed in the lab. 


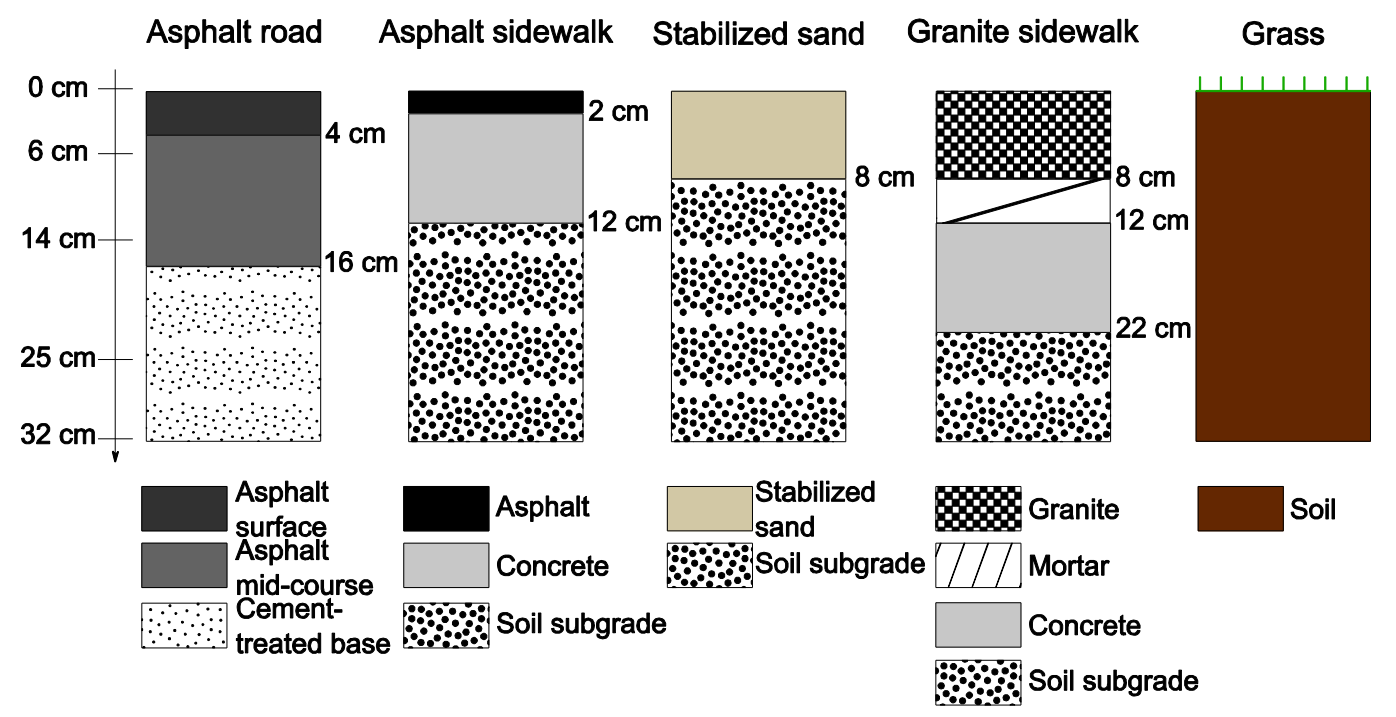

Figure 1: Studied structure samples

Each cylindrical sample is $32 \mathrm{~cm}$ tall and $16 \mathrm{~cm}$ in diameter and is equipped with thermal sensors $0 \mathrm{~cm}$, $6 \mathrm{~cm}, 14 \mathrm{~cm}$ and $25 \mathrm{~cm}$ deep. Material layers were sawed to allow instrument installation and reassembled using tar for asphalt layers and mortar for concrete or cemented layers. Thermal contact between stabilized sand and granite layers was ensured using thermal paste.

At the surface, a black-painted heatflowmeter and a radiative heatflowmeter are placed side-by-side and simultaneously measure sample surface temperature. At each instrumented depth inside the samples, the sensor is either a combined thermocouple and flowmeter for cohesive materials (asphalt concrete, concrete, stabilized sand or granite) or simply a type-T thermocouple for loose materials (base or subgrade layers, soil). As a result, samples don't have identical instrumentation, e.g. the granite paver sidewalk and asphalt road samples have two flowmeters $(6 \mathrm{~cm}$ and $14 \mathrm{~cm}$ deep) while the grass sample has none. The other samples only have one flowmeter $6 \mathrm{~cm}$ deep. Conductive heat flow measured at depth $z$ is noted $V$ *

Thermal conductivity, density and specific heat of each material layer was characterized using a radiationbased technique suited to construction materials [19]. The samples used for this step are sourced from different material batches and therefore cannot be used directly as a measurement of the properties of those employed in the sample structures. They do however offer a reference value for comparison. The measured properties are summarized in Table 1.

The surface emissivity of each sample structure was determined by the reference black body method [20], [21], with a FLIR B400 infrared (IR) camera with a spectral band of 7.5-13 $\mu \mathrm{m}$ and a piece of black PVC tape as the reference black body with a known-emissivity of 0.95 . Emissivity values are summarized in Table 2.

Table 1: Thermal properties of each material layer (except for soil layers) with $95 \%$ confidence interval

\begin{tabular}{|c|c|c|c|c|c|c|c|c|}
\hline & $\begin{array}{l}\text { Asphalt road } \\
\text { surface } \\
\text { course }\end{array}$ & $\begin{array}{c}\text { Asphalt } \\
\text { mid-course }\end{array}$ & $\begin{array}{l}\text { Cement- } \\
\text { treated base }\end{array}$ & $\begin{array}{c}\text { Asphalt } \\
\text { sidewalk } \\
\text { surface course }\end{array}$ & Concrete & $\begin{array}{l}\text { Stabilized } \\
\text { sand }\end{array}$ & Granite & Mortar \\
\hline$k\left(\mathrm{~W} \cdot \mathrm{m}^{-1} \cdot \mathrm{K}^{-1}\right)$ & $1.77 \pm 0.12$ & $1.63 \pm 0.08$ & $1.18 \pm 0.04$ & $2.01 \pm 0.05$ & $1.96 \pm 0.05$ & $1.20 \pm 0.08$ & $2.31 \pm 0.15$ & $2.90 \pm 0.20$ \\
\hline$\rho\left(\mathrm{kg} \cdot \mathrm{m}^{-3}\right)$ & $2305 \pm 37$ & $2360 \pm 34$ & $1946 \pm 96$ & $2325 \pm 34$ & $2301 \pm 50$ & $2090 \pm 42$ & $2608 \pm 18$ & $2157 \pm 14$ \\
\hline$c_{p}\left(\mathrm{~J} \cdot \mathrm{kg}^{-1} \cdot \mathrm{K}^{-1}\right)$ & $725 \pm 59$ & $806 \pm 118$ & $714 \pm 59$ & $900 \pm 56$ & $777 \pm 10$ & $690 \pm 21$ & $759 \pm 63$ & $946 \pm 85$ \\
\hline
\end{tabular}

Table 2: Emissivity of the cylindrical samples

\begin{tabular}{ccccc}
\hline & Asphalt road & Asphalt sidewalk & Stabilized sand & Granite sidewalk \\
\hline Emissivity & 0.98 & 0.98 & 0.92 & 0.99 \\
\hline
\end{tabular}


Access to a Cary 5 UV-Vis-NIR spectrophotometer with a Spectralon-coated integrating sphere was obtained after the cylindrical samples were constructed. Unfortunately, due to their size, it was not possible to measure their spectral reflectivity with this instrument. Instead, the spectral reflectance from $250 \mathrm{~nm}$ to $2500 \mathrm{~nm}$ at $1 \mathrm{~nm}$ resolution was measured following ASTM E903 for samples of the surface materials obtained from different batches. Differences in the precise composition (formula, aggregate source, ...), surface texture and finish of civil engineering materials cause significant differences in their appearance and radiative properties. For these reasons, these measurements cannot be used to calculate the albedo of the cylindrical samples, though they provide an indication of the value range that can be expected. Solely as a reference point, the albedo values calculated using the halogen lamp spectra provided in the 250-1700 nm band (see next section and Figure 4) are provided in Table 3 alongside typical values found in the literature for the solar spectrum, which typically focus on concrete and asphalt pavements. Very few other materials are analyzed and as a result no values were found in the literature for stabilized sand.

Table 3: Albedo values for the different surface materials using spectral reflectance measurements and the 250-1700 nm spectral irradiance of the halogen lamp and values found in the literature.

\begin{tabular}{ccccc}
\hline & Asphalt road & Asphalt sidewalk & Stabilized sand & Granite sidewalk \\
\hline $\begin{array}{c}\text { Measured albedo } \\
\text { (halogen spectra 250-1700 nm) }\end{array}$ & 0.084 & 0.101 & 0.581 & 0.343 \\
$\begin{array}{c}\text { Albedo values from literature } \\
{[22]-[24]}\end{array}$ & $0.05-0.20$ & - & 0.26 \\
\hline
\end{tabular}

Neither emissivity nor spectral reflectivity were measured for the grass sample as neither of the previous methods are suited for a vegetated surface.

\section{Experimental protocol}

Each sample is thermally insulated with a 5 -cm polyurethane casing and submitted to an identical 24-hour climate cycle, three days in a row. Air temperature and relative humidity are controlled with a climate chamber and irradiance with a seven-bulb dichroic halogen lamp with a color temperature of $6,500 \mathrm{~K}$. The imposed conditions are chosen to be representative of heat-waves in Paris. Wind speed is not directly controlled though air circulation conditions are identical between tests. Figure 2 presents a diagram and photograph of the experimental setup. The characteristics of the climate cycles - as measured inside the chamber and at the sample surface - are described in Table 4 and Figure 3.

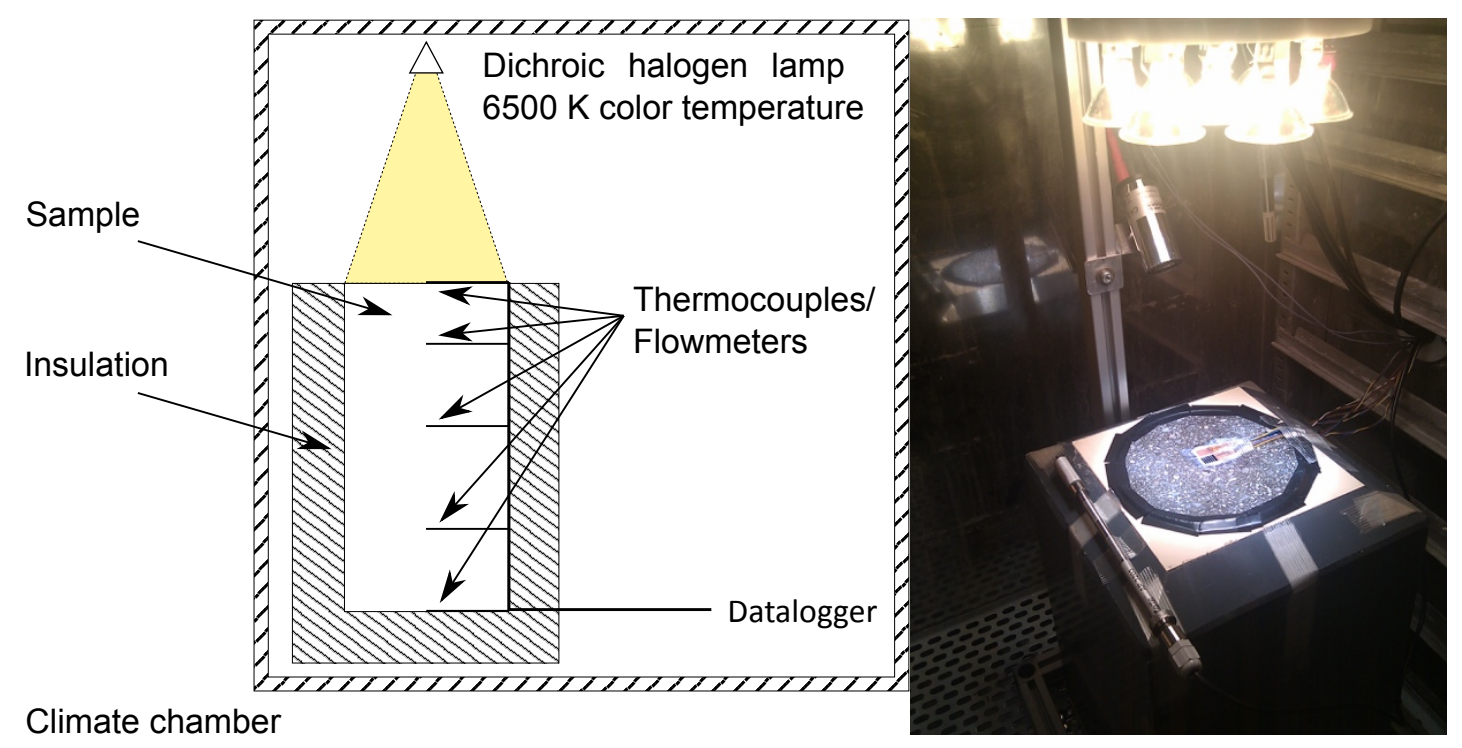

Figure 2: Diagram (left) and photograph (right) of experimental setup. 
Table 4: Daytime and nighttime climate conditions.

\begin{tabular}{ccc}
\hline & Day & Night \\
\hline Duration & $8 \mathrm{~h}$ & $16 \mathrm{~h}$ \\
Air temperature & $35^{\circ} \mathrm{C}$ & $25^{\circ} \mathrm{C}$ \\
Relative Humidity & $35 \%$ & $70 \%$ \\
Incident SW Radiation & $1320 \mathrm{~W} / \mathrm{m}^{2}$ & 0 \\
Incident LW Radiation & $230 \mathrm{~W} / \mathrm{m}^{2}$ & $440 \mathrm{~W} / \mathrm{m}^{2}$ \\
\hline
\end{tabular}
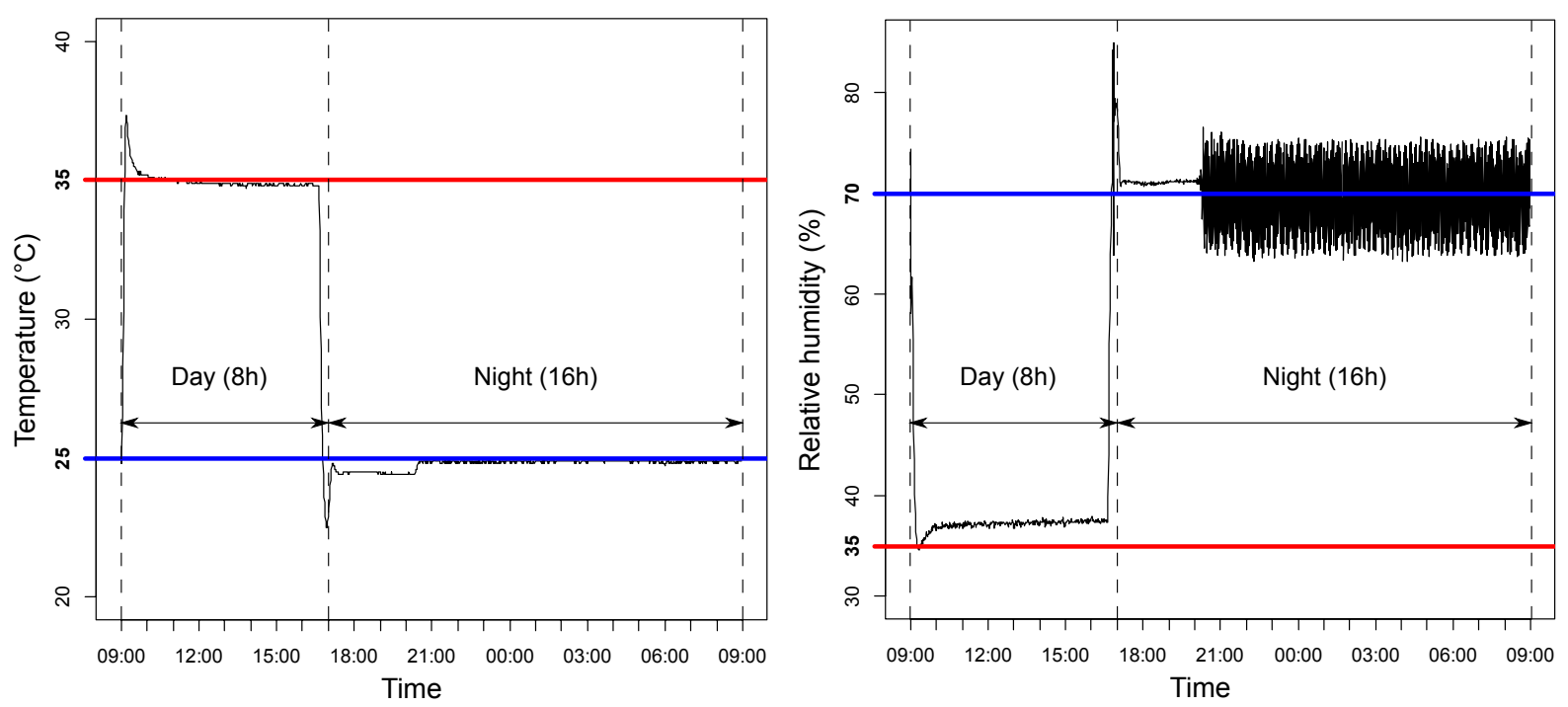

Figure 3: Temperature and relative humidity over 24 hours inside the climate chamber. Daytime and nighttime setpoints are indicated with horizontal red and blue lines, respectively.

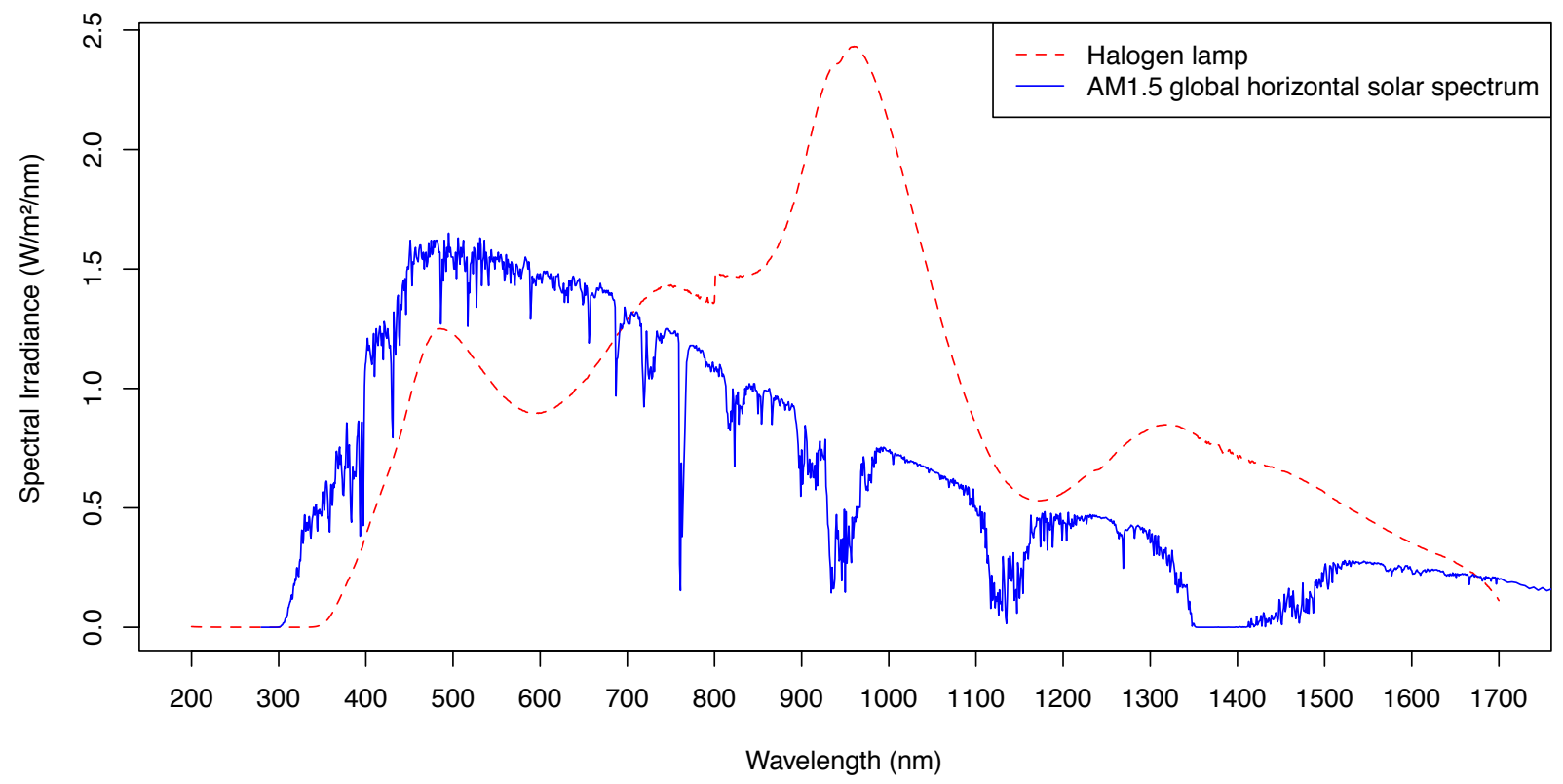

Figure 4: Spectral irradiance of the halogen lamps (dashed) and of the AM1.5 global horizontal solar spectrum (solid) in the $200-1700 \mathrm{~nm}$ band

The irradiance measured at the sample surface is larger-than-expected due to significant internal reflections inside the chamber which has stainless steel interior cladding. The spectral irradiance of the lamp is also 
different from AM1.5. The internal reflections are not expected to modify the resulting spectral irradiance at the sample surface. Figure 4 illustrates spectral irradiance for the halogen lamp in the 200-1 $700 \mathrm{~nm}$ band as provided by the manufacturer with a total irradiance of $1320 \mathrm{~W} / \mathrm{m}^{2}$, compared with that of AM1.5 solar irradiance (total irradiance $1000 \mathrm{~W} / \mathrm{m}^{2}$ ). As can be seen, the halogen lamp's spectra is stronger in the infrared band compared to AM1.5 and slightly lower in the UV or visible bands.

Prior to the beginning of the three-day trials, each sample was stabilized for at least 24 hours in the climate chamber under nighttime conditions. In addition, the grass sample was amply watered before the trials to ensure that evapotranspiration would not be interrupted over the course of the three-day trial.

Measurements are conducted at one-minute intervals. Given the characteristics of the climate cycle, the experiment can be used to compare the behavior of different paving structures though this may differ from real conditions.

\section{Heat balance and analyses}

Figure 5 illustrates the energy balance at the sample surface.

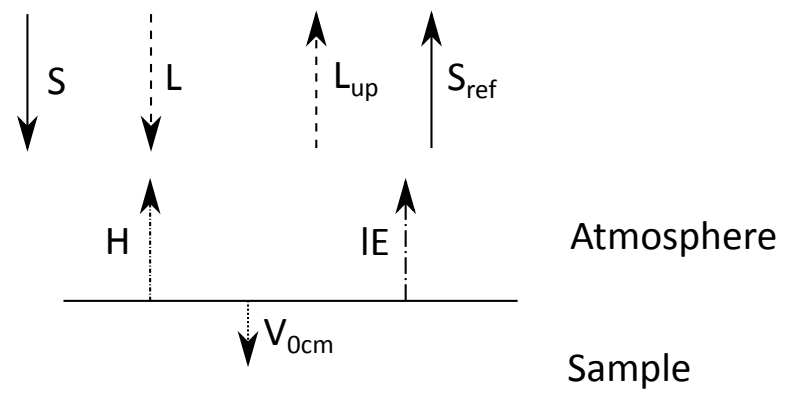

Figure 5: Surface heat budget of a pavement sample

$H=h\left(T_{0 c m}-T_{\text {air }}\right)$ denotes the convective heat flux density from the sample to the atmosphere and is the product of the temperature difference between the air and the surface and the convective heat transfer coefficient $b ; V_{0 \mathrm{~cm}}$ denotes surface conduction into the sample; $l \mathrm{E}$ is the surface latent flux; incident radiation received at the sample surface is noted $S$ and $L$ for shortwave (SW) and longwave (LW), resp., and SW and LW radiosity are noted $S_{r e f}$ and $L_{u p}$, resp. Since the climate chamber is highly reflective, it should be noted that $S$ and $L$ are not solely the result of direct radiation from the lamp, but also of specular and diffuse SW and LW reflection within the climate chamber.

The radiation balance, i.e. the net incident radiation absorbed by a surface of albedo $\alpha$ and emissivity $\varepsilon$, is noted $R_{n}^{\epsilon, \alpha}$ and can be written as follows, with $\sigma$ the Boltzmann constant and $T_{0 \mathrm{~cm}}$ the sample's surface temperature:

$R_{n}^{\varepsilon, \alpha}=S+L-L_{u p}-S_{\text {ref }}=S+L-\alpha S-(1-\varepsilon) L-\varepsilon \sigma T_{0 c m}^{4}$

Furthermore, the surface energy balance can be written as follows:

$R_{n}^{\varepsilon, \alpha}=H+V_{0 c m}+\ell E$

Implementing (1) into (2), we get equation (3), suited to the conditions created in this experiment where $S+L$ is constant across all trials:

$S+L=\alpha S+(1-\varepsilon) L+\varepsilon \sigma T_{0 c m}^{4}+H+V_{0 c m}+\ell E$

In all cases except for the grass sample, $\mathbb{E}$ is equal to zero and is therefore neglected hereafter.

At the surface, the painted global flowmeter (shown unpainted in Figure 2) has an albedo of 0.05 and an emissivity of 0.95 . The flow measured by this sensor is noted $\Phi_{g}$. The radiative flowmeter (striped flowmeter shown in Figure 2) measures net radiation equivalent to that of a black body at the same surface temperature as the sample and under the same irradiance, noted $\Phi_{\text {rad. }}$.

$\Phi_{g}$ and $\Phi_{\text {rad }}$ can be expressed as:

$$
\begin{aligned}
& \Phi_{g}=R_{n}^{\alpha=0,05}-H=0.95 \cdot\left(S+L-\sigma T_{0 \mathrm{~cm}}^{4}\right)-H \\
& \Phi_{\text {rad }}=R_{n}^{\alpha=1}=S+L-\sigma T_{0 \mathrm{~cm}}^{4}=S
\end{aligned}
$$

From equations (4) and (5), we can isolate $H$ : 
Due to the step-curve climate signal that is created inside the climate chamber, the upper layers of the samples are likely to reach semi-steady-state conditions at the end of each day or night phase. Assuming this is the case between depths $z_{n}$ and $z_{n-1}$ (with $z_{n-1}>_{z_{n}}$ ), we obtain equation (7), where $k_{n}$ is the effective thermal conductivity of the layer located between depths $z_{n}$ and $z_{n-1}$ :

$V_{z_{n}}=V_{z_{n-1}}=\frac{k_{n}}{z_{n-1}-z_{n}}\left(T_{z_{n-1}}-T_{z_{n}}\right)$

This assumption is verified as soon as $\left(T_{z_{n-1}}-T_{z_{n}}\right)$ is constant. In particular, once the top $6 \mathrm{~cm}$ layer of a sample reaches semi-steady-state at the end of the day phase, i.e. $\left(T_{0 \mathrm{~cm}}-T_{6 \mathrm{~cm}}\right)$ is constant, $V_{0 \mathrm{~cm}}$ and $V_{6 \mathrm{~cm}}$ are equal. Under these conditions, it is therefore possible to determine the surface albedo from conductive measurements made $6 \mathrm{~cm}$ deep and emissivity $\varepsilon$ using equation (8), derived from implementing equations (4) and (7) into equation (3) as follows:

$H=0.95 \cdot\left(S+L-\sigma T_{0 c m}^{4}\right)-\Phi_{g}$

$V_{0 \mathrm{~cm}}=V_{6 \mathrm{~cm}}$

Therefore:

$S+L=\alpha S+(1-\varepsilon) L+\varepsilon \sigma T_{0 c m}^{4}+0.95 \cdot\left(S+L-\sigma T_{0 c m}^{4}\right)-\Phi_{g}+V_{6 c m}$

$\alpha=0,05+\frac{\Phi_{g}-V_{6 c m}+(\varepsilon-0,95)\left(L-\sigma T_{0 c m}^{4}\right)}{S}$

This equation provides an in situ estimate of the SW reflectivity of the samples to the actual incident irradiance which differs from the solar spectrum, thus eliminating any bias from adopting manufacturer spectral data or assuming purely direct irradiance from the halogen lamp.

In addition, if $V_{z_{n}}$ or $V_{z_{n-1}}$ are measured in addition to $T_{z_{n-1}}$ and $T_{z_{n}}$, then equation (7) can be used to determine the effective thermal conductivity of the n-th layer, i.e. $0-6 \mathrm{~cm}, 6-14 \mathrm{~cm}$ and $14-25 \mathrm{~cm}$. In addition to verifying that $V_{z_{n}}=V_{z_{n-1}}$ or that $\left(T_{z_{n-1}}-T_{z_{n}}\right)$ is constant, using the heat flow measured above (topdown) or below (bottom-up) the layer should provide the same results if the assumption of semi-steadystate conditions is valid.

By determining sample albedo in this way, it is possible to account for the impact of the halogen lamp's spectra on the studied structures and eliminate bias compared to an AM1.5 solar spectra. Indeed, structures with the same AM1.5 albedo would react similarly to the ones studied here, accounting for the increased irradiance.

\section{Atmospheric Heating Index (AHI)}

Pavements contribute to worsening the urban heat island effect when sensible heat $H$ is strictly positive $(H>0)$, i.e. when their surface temperature is greater than air temperature. $H$ can be determined from equation (6), but it can also be indirectly measured from the difference between surface and air temperature measurements $\left(\Delta T=T_{0 \mathrm{~cm}}-T_{\text {air }}\right.$ ) assuming that the convective heat transfer coefficient $b$ does not vary significantly during or between trials, since $H=h\left(T_{0 \mathrm{~cm}}-T_{\text {air }}\right)$.

The cumulative temperature difference, weighted by the time span between measurements, is used as an atmospheric heating index (AHI). Thus constructed, AHI is comparable to the heating degree days (HDD) used to study the energy performance of buildings and uses a commensurable unit: the "degree.hour". As such, $1^{\circ} \mathrm{C} . \mathrm{h}$ for AHI corresponds to a one hour period during which the sample surface is one degree warmer than the air. Built with these assumptions, AHI is commensurable to the sensible heat transferred from the sample to the atmosphere by convection.

\section{Results and Discussion}

\section{Preliminary analysis: thermal and radiative properties}

On the basis of temperature and heat flow measurements, we begin with a preliminary analysis to determine the thermal properties of the sample structures, namely surface albedo and thermal conductivity. Once the albedo of the structures is determined, the surface heat budget in equation (3) can be fully resolved. 


\section{Albedo}

Albedo values determined using equation (8) are summarized in Table 5 calculated during the last hour of the day phase during which $\left(T_{0 \mathrm{~cm}}-T_{6 \mathrm{~cm}}\right)$ is constant for all samples (see Figure 9 and Figure 13).

Table 5: Average albedo and standard deviation obtained from equation (8)

\begin{tabular}{ccccc}
\hline & Asphalt road & Asphalt sidewalk & Stabilized sand & Granite sidewalk \\
\hline Albedo (eq. 8) & $0.128 \pm 0.028$ & $0.193 \pm 0.026$ & $0.414 \pm 0.022$ & $0.342 \pm 0.022$ \\
\hline
\end{tabular}

Overall, significant differences are observed between albedo obtained with equation (8) and spectral reflectivity measurements with the halogen spectrum in Table 3. As previously indicated, this is caused by the fact that material samples are sourced from different batches, except for the granite sidewalk. For this material, for which both samples are extracted from the same source, albedo obtained from spectral reflectivity measurements and equation (8) agree quite well. The other materials, which present visible differences in appearance compared to the ones used with the spectrophotometer, exhibit albedo within the expected value range sourced from the literature and presented in Table 3. As previously noted, no literature values were found for stabilized sand in the literature.

\section{Surface Heat Budget}

From albedo obtained from equation (8) and emissivity measurements, net radiation $R_{n}$ can be calculated using equation (1). It should be noted that changing the value of albedo will only shift $R_{n}$ up or down without affecting its trend. Calculating $H$ from equation (6), surface conduction $V_{0 \mathrm{~cm}}$ can be calculated as the residual of equation (3), thus completing the surface heat budget. These three terms are illustrated in Figure 6. As can be seen, $H$ presents high variability which is transferred to $V_{0 \mathrm{~cm}}$ when resolving equation (3). This variability is interpreted as a result of small-scale turbulence at the sample surface.

It is noteworthy that sensible heat flow $\mathrm{H}$ is never negative despite surface temperatures being lower than air temperature at the beginning of each day phase. This can be seen when comparing the rapid air temperature rise inside the climate chamber from $25^{\circ} \mathrm{C}$ to $35^{\circ} \mathrm{C}$ (Figure 3) and the rate of surface temperature rise from the initial $22-23^{\circ} \mathrm{C}$ (see Figure 9 in the Surface temperature section). This demonstrates that one-minute measurements aren't frequent enough to capture this period in our test conditions. Since this period is very short, it is practically negligible (a few minutes vs. several hours) in comparison to the rest of the day phase during which surface temperatures largely exceed air temperature. 

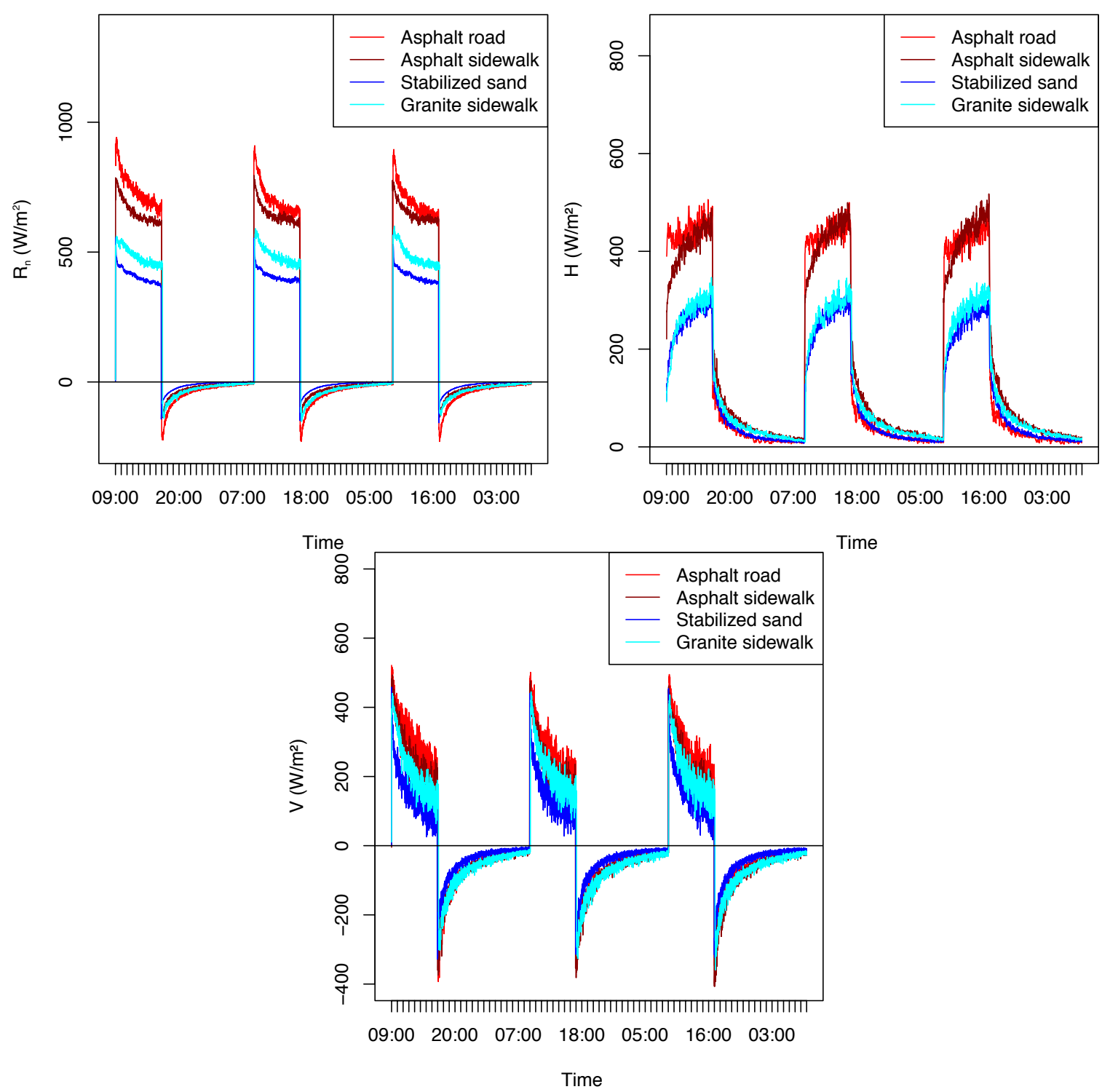

Figure 6: Net radiation $\mathrm{R}_{n}$ (top left), surface convection $H$ (top right) and surface conduction $V$ (bottom) calculated for each sample from the surface heat budget.

\section{Thermal conductivity}

Figure 7 and Figure 8 respectively illustrate effective thermal conductivity of the $0-6 \mathrm{~cm}$ and $6-14 \mathrm{~cm}$ layers obtained from equation (7) with both top-down (left) and bottom-up (right) methods during the last two hours of the day phase of each test day. For lack of a heat flowmeter $14 \mathrm{~cm}$ deep, the conductivity of the 6$14 \mathrm{~cm}$ layer of the asphalt sidewalk and stabilized sand samples can only be determined with the top-down method. It should be noted that the strong signal noise in the top-down calculation for the $0-6 \mathrm{~cm}$ layer is caused by the high variance of $V_{0 \mathrm{~cm}}$. Since $V_{0 \mathrm{~cm}}$ is calculated as the residual of the surface heat balance and given the stability of $R_{h}$, this variability is inherited from $H$, as discussed in the previous section and visible in Figure 6. 

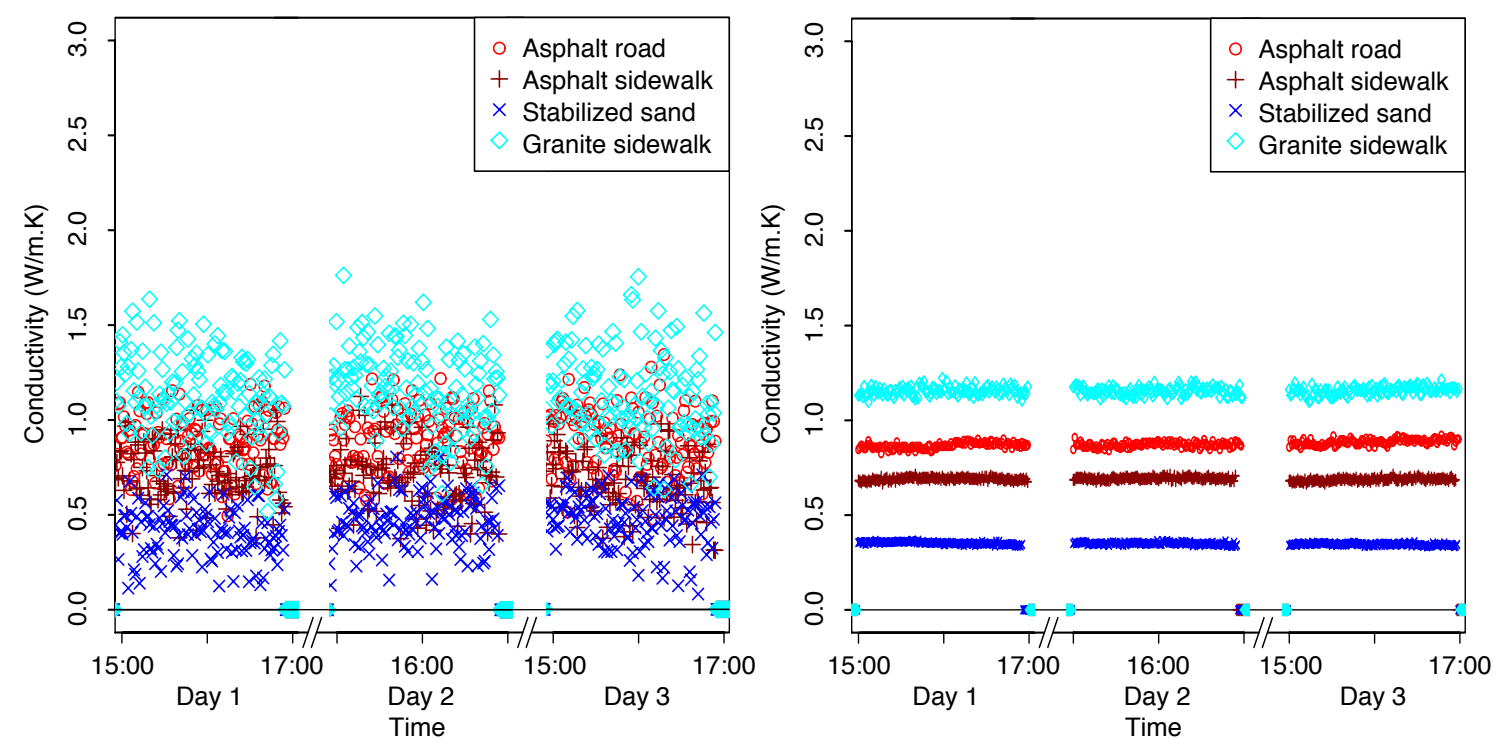

Figure 7: Effective thermal conductivity of 0-6 cm layer (left: top-down; right: bottom-up)
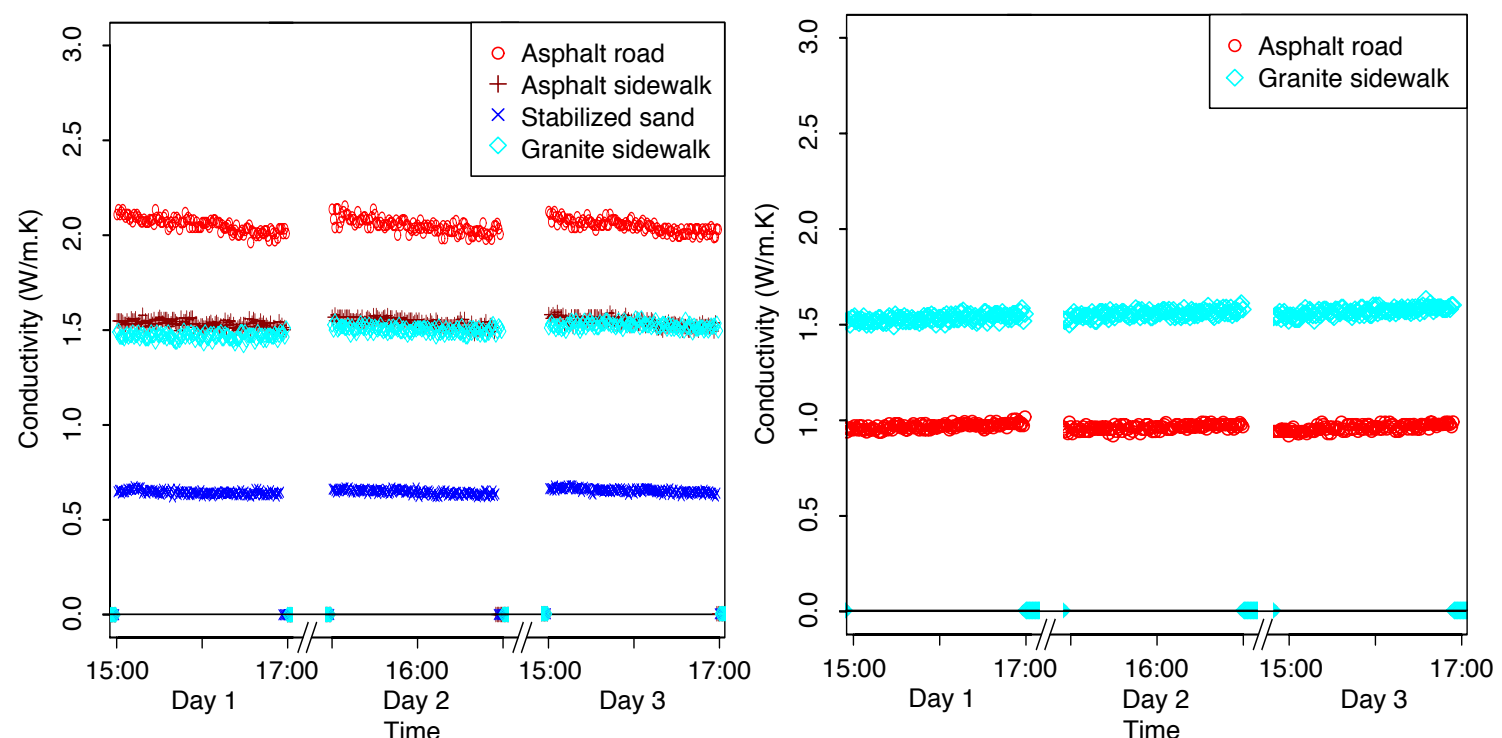

Figure 8: Effective thermal conductivity of 6-14 cm layer (left: top-down; right: bottom-up)

The use of equation (7) is based on the assumption that the considered layers have reached semi-steadystate, i.e. that $V_{z_{n}}$ and $V_{z_{n-1}}$ are equal and constant or that $\left(T_{z_{n-1}}-T_{z_{n}}\right)$ is constant. In addition, results from the top-down and bottom-up approaches should be the same. These conditions are verified for all layers of all the samples where data is available, except for the 6-14 cm layer of the asphalt road structure. In this case, $\left(T_{6 \mathrm{~cm}}-T_{14 \mathrm{~cm}}\right)$ is constant, $V_{6 \mathrm{~cm}}$ and $V_{14 \mathrm{~cm}}$ are constant, but $V_{6 \mathrm{~cm}}=V_{14 \mathrm{~cm}}+100 \mathrm{~W} / \mathrm{m}^{2}$, in addition to the top-down and bottom-up methods yielding significantly different results.

This is either caused by instrument error or thermal leakage. However, the insulation casing is the same for all samples and no leakage is visible in the case of the granite sidewalk sample which verifies the semi-steadystate assumptions in every respect. We therefore conclude that the $14 \mathrm{~cm}$ deep flowmeter of the road sample is defective and only retain the top-down estimate of effective thermal conductivity.

Values obtained during the last hour, i.e. the last 180 observations, are used to calculate the values summarized in Table 6 . As can be seen, the top $0-6 \mathrm{~cm}$ layer of the asphalt road and sidewalk have similar conductivity $\pm 0.20 \mathrm{~W} / \mathrm{m} . \mathrm{K}$. This similarity is confirmed when considering surface and 6 -cm temperatures later on in Figure 9 and Figure 13 where both structures exhibit similar behavior, considering their similar albedo. The thermal conductivity of the $6-14 \mathrm{~cm}$ layer however is $0.5 \mathrm{~W} / \mathrm{m} . \mathrm{K}$ lower for the asphalt sidewalk than the asphalt road, as can be seen when comparing 6-cm and 14-cm temperatures in Figure 13. 
Table 6: Average effective thermal conductivity of 0-6 and 6-14 cm layers and standard deviation.

\begin{tabular}{cccccc}
\hline & & Asphalt road & Asphalt sidewalk & Stabilized sand & Granite sidewalk \\
& Top-down & $0.90 \pm 0.16$ & $0.70 \pm 0.16$ & $0.45 \pm 0.14$ & $1.16 \pm 0.23$ \\
& & & & & \\
& Bottom-up & $0.88 \pm 0.022$ & $0.69 \pm 0.008$ & $0.35 \pm 0.007$ & $1.16 \pm 0.022$ \\
$6-14 \mathrm{~cm}$ & Top-down & $2.03 \pm 0.026$ & $1.52 \pm 0.016$ & $0.64 \pm 0.009$ & $1.49 \pm 0.028$ \\
& Bottom-up & - & - & - & $1.56 \pm 0.023$ \\
\hline
\end{tabular}

These eight observations are insufficient to determine the conductivity of the nine different materials without making further assumptions. To solve this problem, it was assumed that two of the material layers had identical thermal conductivity. After testing likely candidates, assuming that the soil subgrade and cement-treated base have identical thermal conductivity provided the most realistic results in regards with thermal conductivity found in the literature [25]-[27]. The obtained conductivities are summarized in Table 7 and compared with the values expected from the individual material properties summarized in Table 1.

Table 7: Conductivity of each material layer determined from effective layer conductivity (in $\mathrm{W} \cdot \mathrm{m}^{-1} \cdot \mathrm{K}^{-1}$ ). The conductivity of the soil subgrade is assumed equal to that of the cement-treated base.

\begin{tabular}{|c|c|c|c|c|c|c|c|c|c|}
\hline & $\begin{array}{l}\text { Asphalt } \\
\text { road } \\
\text { surface } \\
\text { course }\end{array}$ & $\begin{array}{l}\text { Asphalt } \\
\text { mid- } \\
\text { course }\end{array}$ & $\begin{array}{c}\text { Cement- } \\
\text { treated } \\
\text { base }\end{array}$ & $\begin{array}{l}\text { Asphalt } \\
\text { sidewalk } \\
\text { surface } \\
\text { course }\end{array}$ & Concrete & $\begin{array}{l}\text { Stabilized } \\
\text { sand }\end{array}$ & Granite & Mortar & $\begin{array}{c}\text { Soil } \\
\text { subgrade }\end{array}$ \\
\hline Observed & 0.69 & 2.11 & 0.80 & 0.30 & 2.18 & 0.40 & 1.16 & 1.54 & 0.80 \\
\hline $\begin{array}{l}\text { Values } \\
\text { from } \\
\text { Table } 1\end{array}$ & $\begin{array}{c}1.77 \\
\pm 0.12\end{array}$ & $\begin{array}{c}1.63 \\
\pm 0.08\end{array}$ & $\begin{array}{c}1.18 \\
\pm 0.04\end{array}$ & $\begin{array}{c}2.01 \\
\pm 0.05\end{array}$ & $\begin{array}{l}1.96 \\
\pm 0.05\end{array}$ & $\begin{array}{l}1.20 \\
\pm 0.08\end{array}$ & $\begin{array}{c}2.31 \\
\pm 0.15\end{array}$ & $\begin{array}{c}2.90 \\
\pm 0.20\end{array}$ & - \\
\hline
\end{tabular}

As can be seen, observed and expected values contrast strongly, particularly for surface materials. Plausible reasons are manifold and it is unclear which is dominant. Firstly, it should be kept in mind that, as with spectral reflectance measurements, the samples used in both methods are sourced from different batches. This inevitably introduces differences in material properties, particularly for mixed materials such as asphalt or cement concrete. However, this explanation is insufficient. The most likely explanation is poor thermal contact at material interfaces, i.e. between material layers and where instruments are placed. Indeed, this explains the strong difference observed for granite, which is the only material where all samples are sourced from the same $40 \times 60 \times 8 \mathrm{~cm}$ paver.

Other possible factors are thermal leakage, but it is not expected to be sufficiently significant in the upper layers to explain these discrepancies, particularly given that heatflow $6 \mathrm{~cm}$ and $14 \mathrm{~cm}$ deep are nearly equal in the case of the granite sidewalk structure (see Figure 14). Finally, surface temperature overestimation, due to the sensors' direct exposure to incident irradiance and imperfect thermal contact with the sample surface, may also result in effective surface course conductivity underestimation.

Regardless, these thermal conductivity results are not used hereafter, except in the Discussion section.

\section{Surface temperature}

We begin by describing surface temperature observations. Figure 9 presents surface temperature measurements for each pavement structure sample conducted over three consecutive days. 


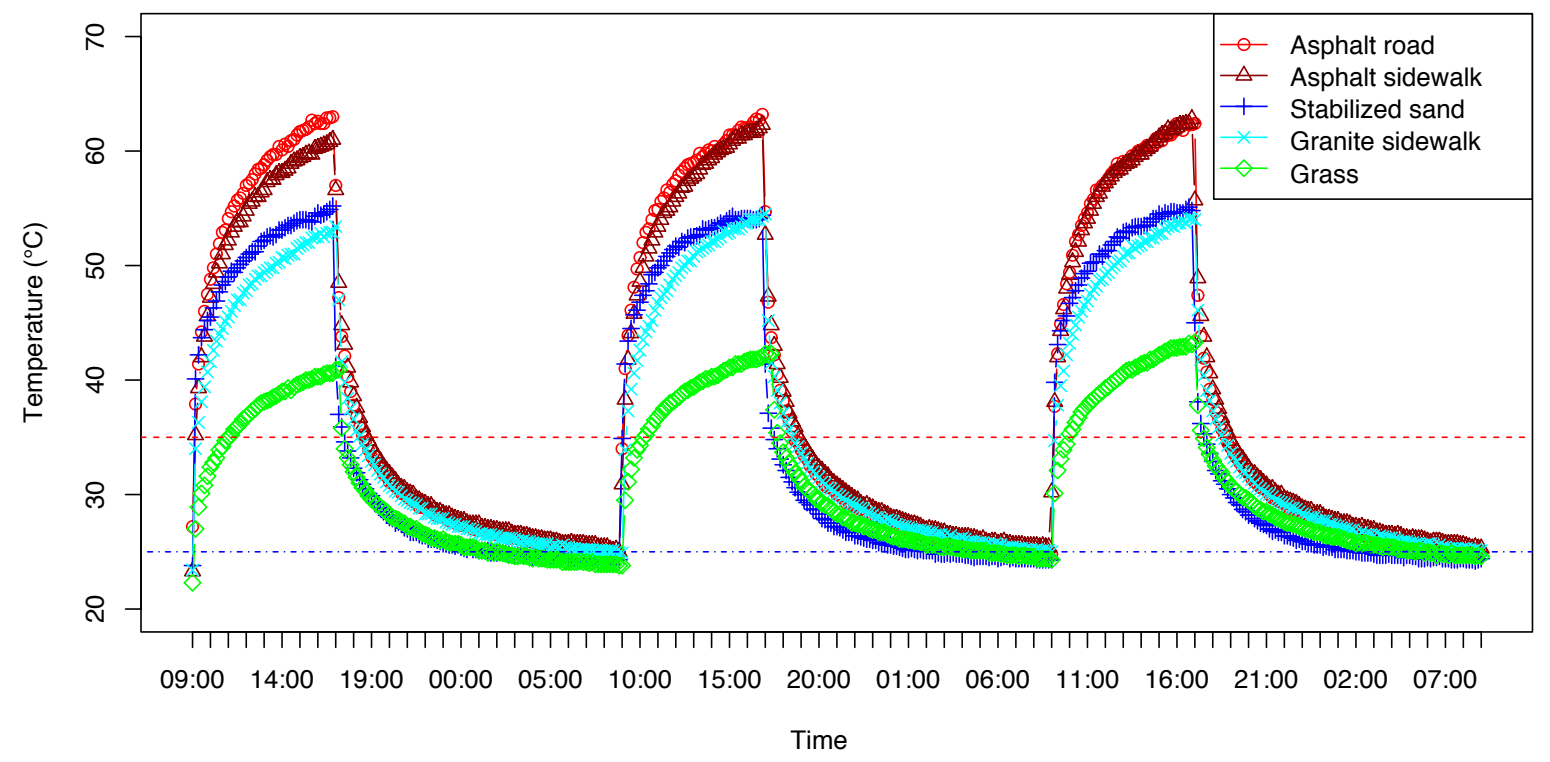

Figure 9: Surface temperatures measured over three consecutive days. Dashed red and dotted blue horizontal lines resp. represent daytime $\left(35^{\circ} \mathrm{C}\right)$ and nighttime $\left(25^{\circ} \mathrm{C}\right)$ air temperature setpoints.

\section{Day 1}

Structures begin the day phase with an exponential temperature rise from an initial surface temperature of approximately $23^{\circ} \mathrm{C}$. At the end of the day phase, two categories of structures can be distinguished on the basis of their surface temperature: "hot" materials, whose temperature exceeds $60^{\circ} \mathrm{C}$, and "cool" materials that remain below $55^{\circ} \mathrm{C}$. Dark-colored structures, i.e. the asphalt road and sidewalk which have the lowest albedo, belong to the first category, while stabilized sand, granite sidewalk and grass belong to the second category. Grass, more than $10^{\circ} \mathrm{C}$ cooler than the other two "cool" structures, could constitute its own category of "very cool" materials.

After 8 hours of sunshine the lamp is turned off and air temperature is suddenly decreased to $25^{\circ} \mathrm{C}$, followed by an exponential drop in temperatures which decline towards their initial values. All structures end the cycle with higher temperature than at the start of Day 1.

At night, the structures can be separated into two groups: the stabilized sand and grass samples being the coolest on the one hand, and the remaining, significantly warmer, structures on the other. The granite sidewalk structure, although classified as a cool material during the day, reaches the temperature level of low-albedo structures during the night. In addition, the asphalt road, which was the warmest structure during the day, becomes cooler than the asphalt sidewalk.

Figure 10 plots the daily maximum surface temperature increase relatively to air temperature observed for all samples from Day 1 to 3 against albedo (Table 5). The linear regression line for all data points excluding the grass sample is also plotted.

These data indicate that under these climate conditions (air temperature of $35^{\circ} \mathrm{C}$ and $\mathrm{SW}$ irradiance of 1320 $\mathrm{W} / \mathrm{m}^{2}$ ) for every 0.1 increase in albedo, daily maximum surface temperature is decreased by approximately $3.4^{\circ} \mathrm{C}$. This value is within the range of $3-7^{\circ} \mathrm{C}$ per 0.1 albedo increase found in the literature for pavements or roof tiles under similar conditions [12], [28]-[32].

Figure 11 illustrates AHI during the first day for each structure. Daytime contributions are shown in red (bottom of histograms) while nighttime contributions are shown in blue (top). Daytime heating is significantly greater than nighttime heating for all samples except the grass sample. However, the nocturnal contributions are not negligible and are even decisive for ranking the samples by their AHI. While the grass sample contributes the least to atmospheric heating, low-albedo materials contribute the most, followed by lighter-colored materials. 


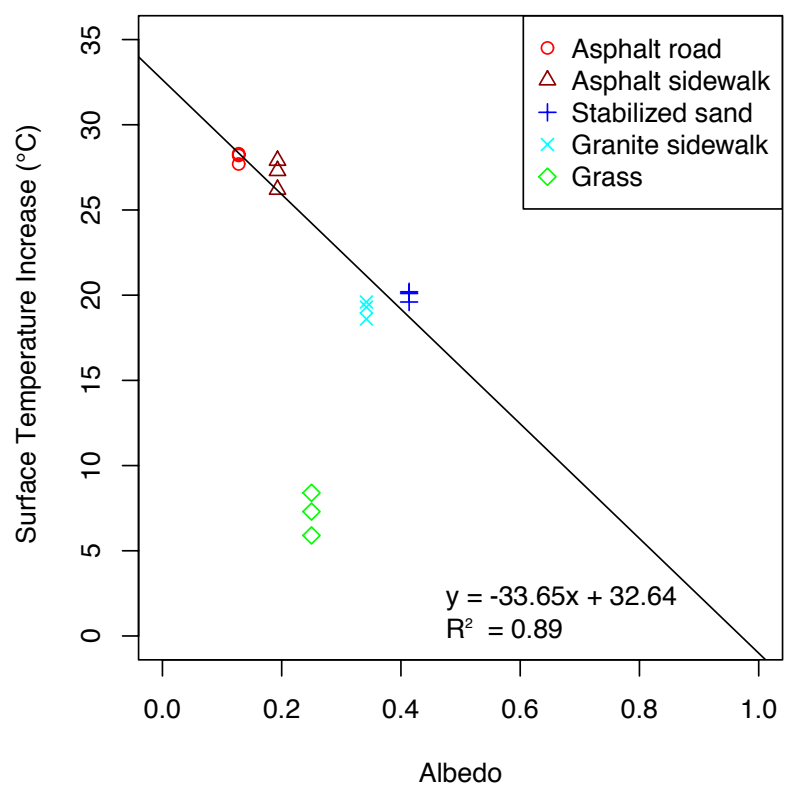

Figure 10: Daily maximum surface temperature as a function of surface albedo

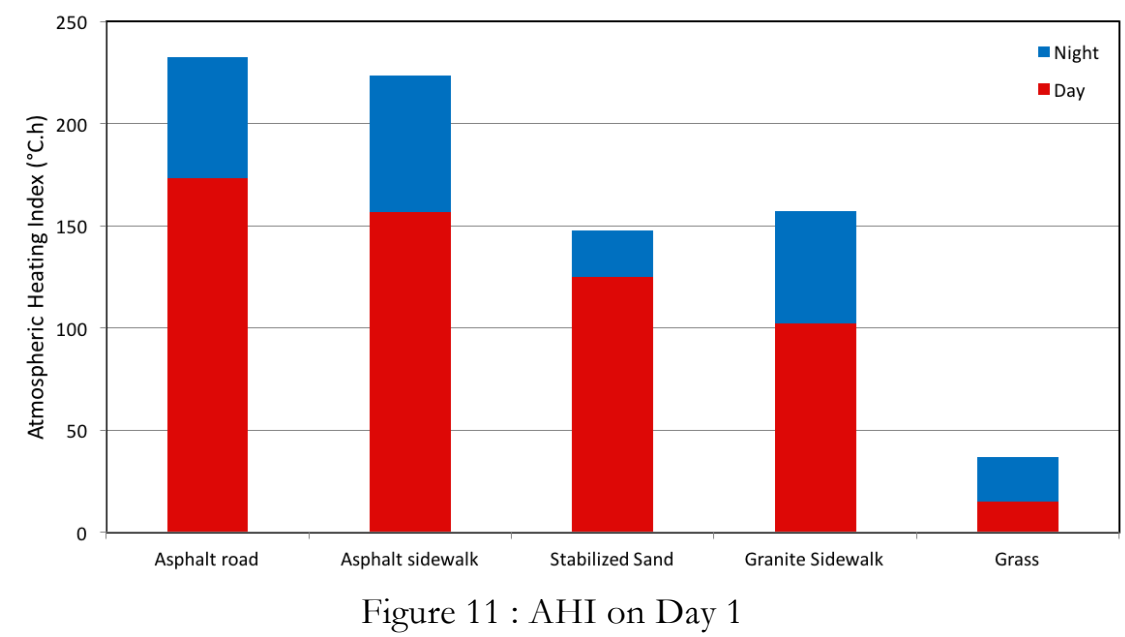

As a first approach, these behaviors are well explained by surface albedo for the pavements, which governs the radiation absorbed by each sample, and by evapotranspiration for the grass structure. However, this is not sufficient to explain daytime and nighttime AHI observations. Indeed, Table 8 presents 24-hour cumulative net radiation, illustrated in Figure 6, for each sample on Day 1. According to the surface heat budget, this term is equal to the sum of daily heat storage and daily sensible heat transfer.

Table 8: Daily net radiation on Day $1\left(\mathrm{kWh} / \mathrm{m}^{2}\right)$

\begin{tabular}{cccc}
\hline Asphalt road & Asphalt sidewalk & Stabilized sand & Granite sidewalk \\
\hline 5,3 & 4,9 & 3,0 & 3,5 \\
\hline
\end{tabular}

Relative daily net radiation levels correlate well with relative levels of daily AHI. However, greater detail is needed to understand the behaviors observed during the day and night phases. Indeed, the granite sidewalk behaves very similarly to dark structures during the night phase while it absorbs much less radiation than they do. Moreover, it is cooler during the day than stabilized sand even though it has higher daily net radiation.

These two observations can be explained by the granite structure's high effusivity $\left(\sqrt{k \rho c_{p}}\right)$ and diffusivity $\left(\frac{k}{\rho c_{p}}\right)$. High effusivity ensures low temperature rise during rapid heat absorption, while high diffusivity means that the surface temperature signal is transmitted in depth quickly. These properties allow the granite structure to rapidly store a large portion of the absorbed radiation in depth during the day, while limiting 
surface heating. At night, the same phenomenon rapidly releases the heat accumulated during the day and thus maintains high temperatures, making the granite sidewalk as warm as the asphalt structures.

These observations are confirmed when temperatures and flows are observed at other depths (see below).

\section{Cumulative effects}

Cumulative effects can be observed by comparing surface temperature between Day 1 and Day 3. Indeed, after three consecutive days, the structures show varying signs of heat accumulation. Specifically, if the behavior of the asphalt road and the stabilized sand samples is only slightly modified on Day 3 compared to Day 1, this is not the case for asphalt and granite sidewalks, nor grass. These samples suffer the greatest increase in surface temperature as test cycles are conducted, as shown by their maximum daily surface temperatures summarized in Table 9.

Table 9: Maximum surface temperature on Day 1, Day 2 and Day 3.

\begin{tabular}{llll}
\hline Structure & $\mathrm{T}_{\max }$ on Day $1\left({ }^{\circ} \mathrm{C}\right)$ & $\mathrm{T}_{\max }$ on Day $2\left({ }^{\circ} \mathrm{C}\right)$ & $\mathrm{T}_{\max }$ on Day $3\left({ }^{\circ} \mathrm{C}\right)$ \\
\hline Asphalt road & 63,3 & 63,2 & 62,7 \\
Asphalt sidewalk & 61,2 & 62,3 & 62,9 \\
Stabilized sand & 55,2 & 54,6 & 55,1 \\
Granite sidewalk & 53,6 & 54,6 & 54,3 \\
Grass & 40,9 & 42,3 & 43,4 \\
\hline
\end{tabular}

During the day, the temperature of the asphalt and granite sidewalks gradually increases as they catch up with the road and stabilized sand structures, respectively. Grass experiences the largest increase. At night, the behavior is not significantly modified on Day 3 compared to Day 1, except for the grass sample which becomes warmer than stabilized sand.

Similar observations can also be made on the basis of AHI, presented in Figure 12 for Day 3.

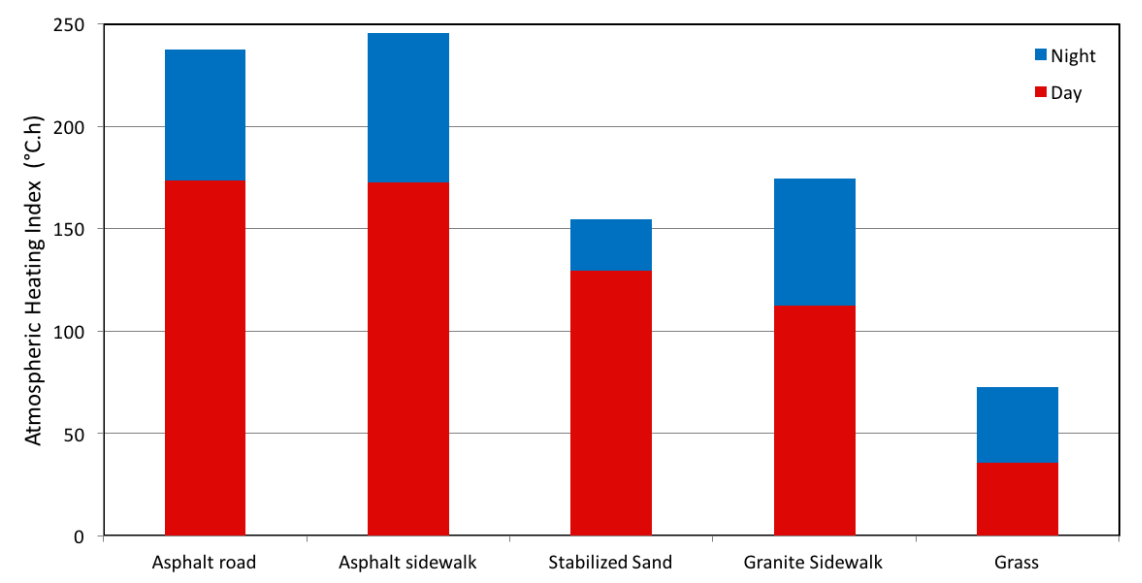

Figure 12: AHI on Day 3.

Compared to those calculated on Day 1, all contributions observed on Day 3 have increased. Asphalt road and stabilized sand are the least affected structures with an increase of less than $5 \%$, while the AHI of grass almost doubles, even if it remains by far the smallest in absolute terms. Atmospheric heating by asphalt and granite sidewalks increases by about $10 \%$. This means that the asphalt sidewalk overtakes the asphalt road as the structure with the highest AHI on Day 3.

The grass and sidewalk structures are therefore the most affected by the cumulative effects caused by the sequence of three "heat-wave" days. This is attributed to their high thermal inertia. If the water content of the lawn sample is the reason for its high inertia, that of the sidewalk structures is attributed to their concrete foundation which is highly effusive and diffusive, effectively serving as a thermal store.

This inertia allows these structures to cushion temperature rises during heat-waves. This is an interesting property if the event is short-lived, but this advantage is lost in the case of a long-lived one during which inertia then serves the opposite role, i.e. tending to prolong the heat-wave once it has passed. 
Several studies have focused on the impact of the thermal conductivity or inertia of pavements on their contribution to atmospheric heating [12], [33]-[36]. This work indicates that the potential of these properties is limited in regards to changes in reflectivity or surface evaporation. The comparison between the AHI of the asphalt road and sidewalk structures results in a similar conclusion: despite higher inertia, the asphalt sidewalk remains comparable to the asphalt road due to its low albedo. Switching to a high-albedo structure would be more beneficial, even with low inertia, e.g. stabilized sand. The change in the AHI of the sidewalk structures between Day 1 and Day 3, which provides an estimate of the cooling that can be obtained with high inertia, is comparable to that found by other authors [12], [33]-[36].

\section{Temperatures below the surface}

Figure 13 illustrates temperature measured $6 \mathrm{~cm}$ (top left), $14 \mathrm{~cm}$ (top right) and $25 \mathrm{~cm}$ (bottom) deep inside each sample.

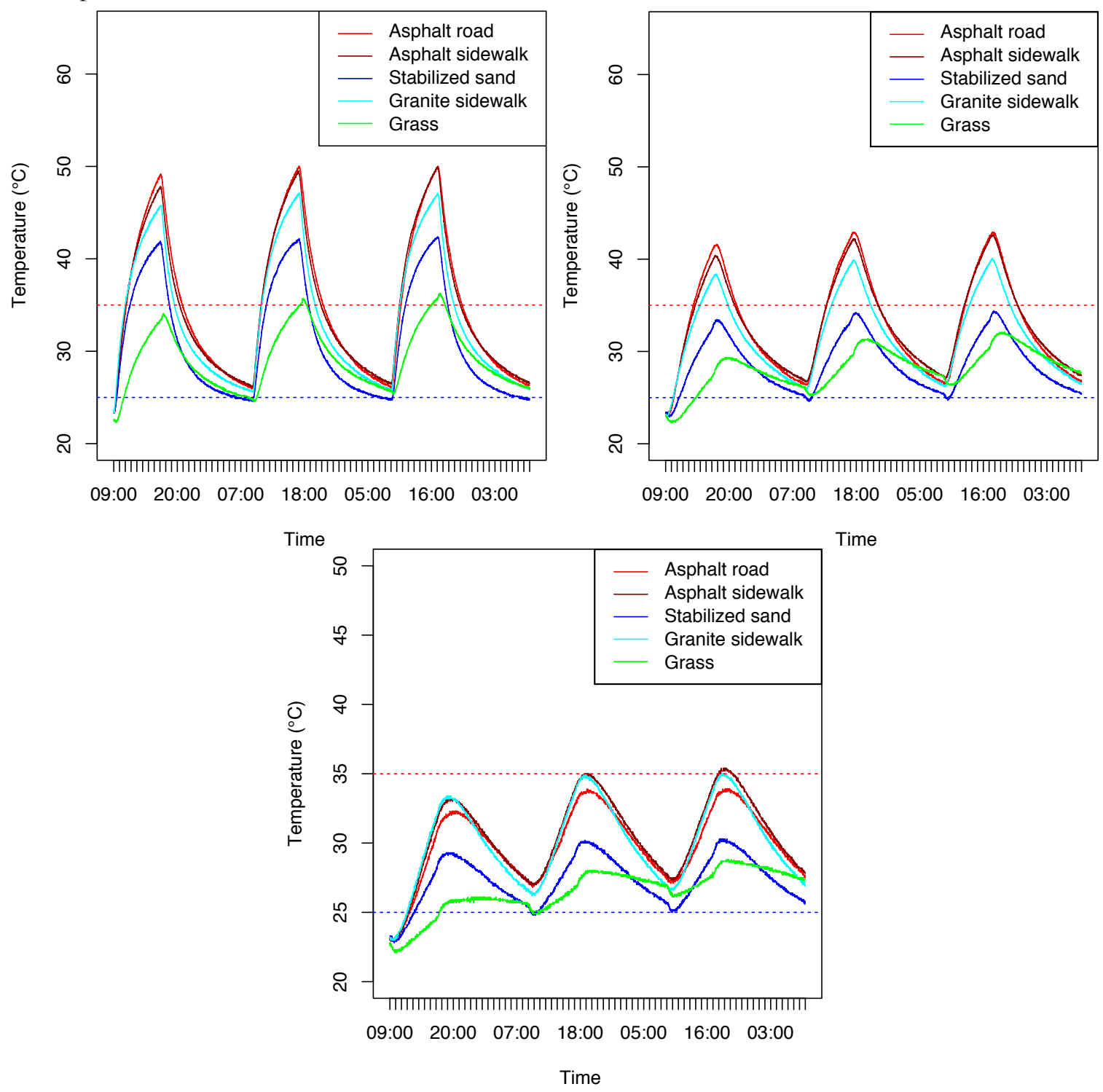

Figure 13: Temperature measured $6 \mathrm{~cm}$ (top left), $14 \mathrm{~cm}$ (top right) and $25 \mathrm{~cm}$ (bottom) deep over

72 hours. The dotted red and blue lines resp. indicate the day and night setpoint temperatures.

Similar patterns to those seen for surface temperatures are observed at these depths, though the gap between "cool" and "hot" structures narrows as depth increases. Of all samples, signal dampening is strongest for the grass structure, especially $25 \mathrm{~cm}$ deep. After 24 hours, temperatures remain a few degrees warmer than they were at the beginning of the cycle at all depths, as was also the case for surface temperatures, an indication of heat accumulation. 
Despite many similarities, differences at these depths stand out compared to surface temperature observations. Most striking, the granite sidewalk is much warmer than the stabilized sand structure at $6 \mathrm{~cm}$ and $14 \mathrm{~cm}$ depth and at $25 \mathrm{~cm}$ even becomes warmer than the asphalt road structure and nearly matches the asphalt sidewalk. At these depths, its thermal behavior downgrades it from the "cool" category to the "hot" one alongside the asphalt road and sidewalk structures.

Also, the previously barely-perceptible differences at night between the stabilized sand and grass samples become more and more pronounced with increasing depth, resulting in stabilized sand becoming significantly cooler than grass during this phase. During the day, stabilized sand remains significantly warmer than grass.

Additionnally, inertial effects are visible from the gradual increase in temperatures over the course of the three-day trial. Maximum temperature increases at each depth are summarized in Table 10 for each sample. By this metric, the grass and asphalt sidewalk structures have the highest inertia among the considered structures, while the stabilized sand has the lowest.

Table 10: Daily maximum temperature increase on Day 3 compared to Day 1 by depth

\begin{tabular}{lrrr}
\hline Structure & $6 \mathrm{~cm}$ & $14 \mathrm{~cm}$ & $25 \mathrm{~cm}$ \\
\hline Asphalt road & $+0.8^{\circ} \mathrm{C}$ & $+1.3^{\circ} \mathrm{C}$ & $+1.6^{\circ} \mathrm{C}$ \\
Asphalt sidewalk & $+2.2^{\circ} \mathrm{C}$ & $+2.2^{\circ} \mathrm{C}$ & $+2.2^{\circ} \mathrm{C}$ \\
Stabilized sand & $+0.5^{\circ} \mathrm{C}$ & $+1{ }^{\circ} \mathrm{C}$ & $+1{ }^{\circ} \mathrm{C}$ \\
Granite sidewalk & $+1.3^{\circ} \mathrm{C}$ & $+1.7^{\circ} \mathrm{C}$ & $+1.6^{\circ} \mathrm{C}$ \\
Grass & $+2.2^{\circ} \mathrm{C}$ & $+2.8^{\circ} \mathrm{C}$ & $+2.7^{\circ} \mathrm{C}$ \\
\hline
\end{tabular}

Finally, signal shifts are also visible with increasing depth, inversely proportional to thermal diffusivity. Table 11 summarizes the delay in peak temperature by depth and by structure compared to the occurrence of the surface temperature peak. As can be seen, grass exhibits the lowest thermal diffusivity at all depths, while the granite sidewalk has the highest diffusivity, followed by asphalt sidewalk, asphalt road and stabilized sand.

Table 11: Average signal shift measured by time lag of peak temperature compared to surface peak

\begin{tabular}{lrrrr}
\hline Structure & $6 \mathrm{~cm}$ & $14 \mathrm{~cm}$ & $25 \mathrm{~cm}$ \\
\hline Asphalt road & $9 \mathrm{~min}$ & $39 \mathrm{~min}$ & $2 \mathrm{~h}$ & $9 \mathrm{~min}$ \\
Asphalt sidewalk & $4 \mathrm{~min}$ & $32 \mathrm{~min}$ & $2 \mathrm{~h}$ & $0 \mathrm{~min}$ \\
Stabilized sand & $19 \mathrm{~min}$ & $59 \mathrm{~min}$ & $1 \mathrm{~h} 48 \mathrm{~min}$ \\
Granite sidewalk & $1 \mathrm{~min}$ & $32 \mathrm{~min}$ & $1 \mathrm{~h} 36 \mathrm{~min}$ \\
Grass & $40 \mathrm{~min}$ & $2 \mathrm{~h} 25 \mathrm{~min}$ & $3 \mathrm{~h} 20 \mathrm{~min}$ \\
\hline
\end{tabular}

\section{Pavement heat flow}

Heatflow measurements at 6 and $14 \mathrm{~cm}$ also support previous observations and analyses. Figure 14 shows the conductive flux measured in the samples 6 and $14 \mathrm{~cm}$ deep.

Heatflow measured 6 and $14 \mathrm{~cm}$ deep exhibit a similar pattern: positive (downward) during the 8-hour day phases and negative (upward) during the night phases. At $6 \mathrm{~cm}$ depth, the asphalt road has the highest conduction amplitude, followed by the asphalt and granite sidewalks which are nearly identical, while stabilized sand has the lowest. At a depth of $14 \mathrm{~cm}$, the granite sidewalk conducts nearly as much heat as $6 \mathrm{~cm}$ deep. Unfortunately, the $14 \mathrm{~cm}$ deep heatflowmeter in the asphalt road is defective and cannot be used.

The similar behavior of the asphalt and granite sidewalk samples contrasts sharply with temperature observations. The granite sidewalk conducts as much heat $6 \mathrm{~cm}$ below the surface as the asphalt sidewalk despite being much cooler and having higher albedo. Identical heat flow 6 and $14 \mathrm{~cm}$ deep is also striking, confirming that the granite sidewalk structure has reached steady-state up to $14 \mathrm{~cm}$ deep. These elements add to the body of evidence supporting that this highly conductive sample stores a large portion of absorbed irradiance in its lower layers, limiting daytime surface temperature but increasing it at night. 

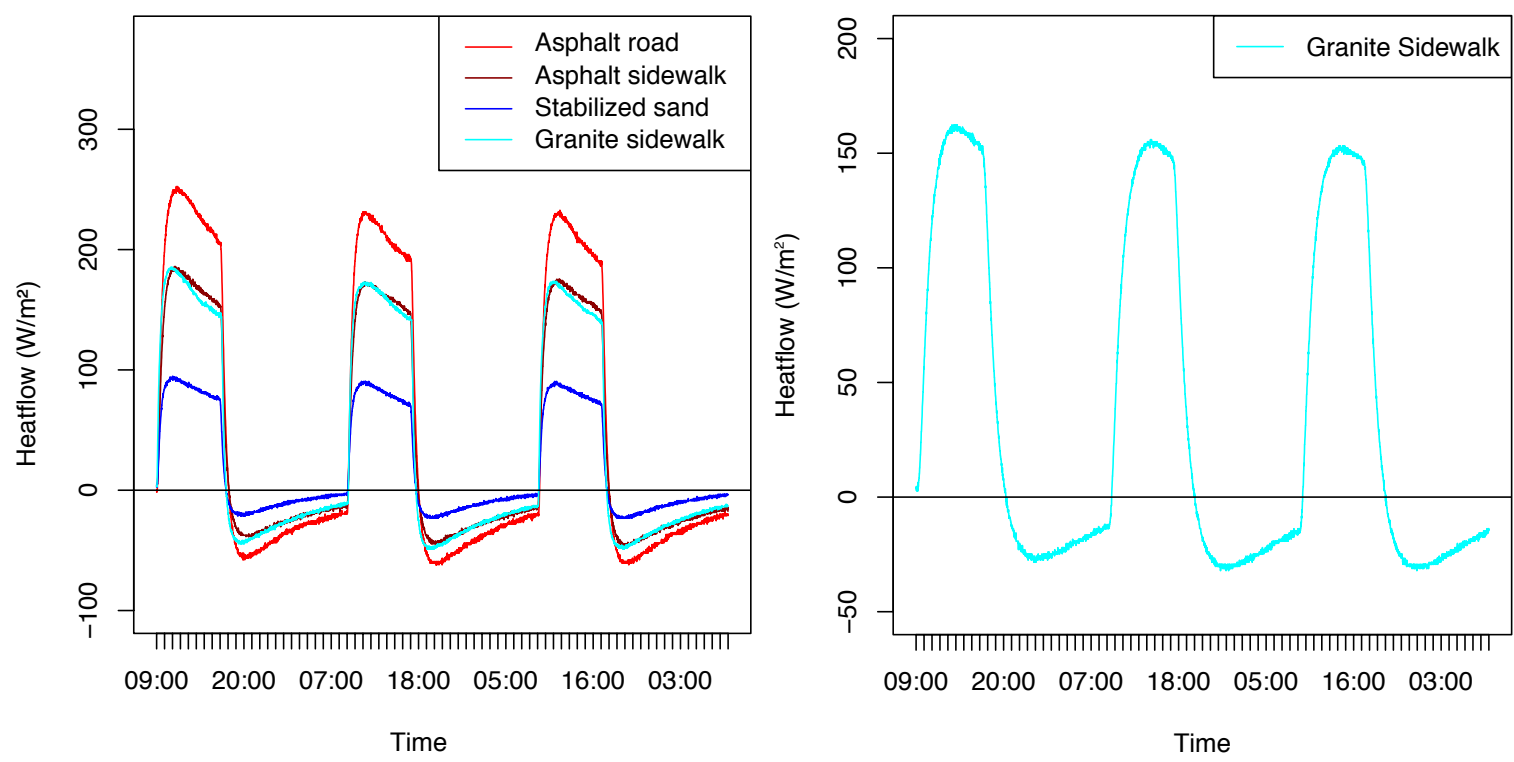

Figure 14 : Conductive heat flux at $6 \mathrm{~cm}$ (left) and $14 \mathrm{~cm}$ (right) depth

\section{Discussion}

Temperatures obtained with this experimental setup compare favorably with other laboratory-scale experiments as well as field observations conducted on an asphalt road structure in Paris over the summer of 2013 under similar weather conditions [8], [17], [18], [37]. In the field, for a pavement area receiving only 4.5 hours of direct sunlight per day and daily maximum air temperature of $35^{\circ} \mathrm{C}$, pavement temperatures reached up to $55^{\circ} \mathrm{C}$ at the surface and $45^{\circ} \mathrm{C} 5 \mathrm{~cm}$ deep. This holds true for $5 \mathrm{~cm}$ deep heat flow as well, which reached up to $200 \mathrm{~W} / \mathrm{m}^{2}$ in the field under those same conditions [11]. Differences between observations can be explained by the climate signal created in the lab, which has longer, stronger and constant insolation. Despite this, the overall trend obtained is satisfactory, with lab conditions being exaggerated compared to field conditions for heat-waves.

Generally-speaking, these temperature observations agree well with the behavior expected of each sample given their surface albedo, with the notable exception of the granite sidewalk structure. Indeed, temperatures similar to those of the stabilized sand would be expected for this structure given their similar albedo. Temperature and heatflow measurements at different depths constitute a body of evidence that point to the granite sidewalk's thermal properties, in particular its high effusivity and diffusivity, as a likely explanation for these observations. As a result, solar irradiance is not only reflected back, it is also transmitted into the deeper layers of the structure, thus explaining the higher-than-expected temperatures and heatflow within the structure.

Overall, the experimental dataset provides a global view of how these structures react to heat-wave conditions and thus contribute to the urban climate compared to one another. The grass and stabilized sand structures are clearly the coolest, while the asphalt structures have similar behavior, the granite sidewalk storing heat during the day which is then released later during the night.

In addition, inertial phenomena are clearly visible in varying intensity, as was described in Table 10. While lower material temperatures will have positive consequences such as lower atmospheric heating in cities, higher inertia will slow temperature increases when a heat spike arises. Ideally, urban pavement structures should therefore combine both properties thanks to the use of high albedo surface materials with concrete sublayers for example. The urban materials used in Paris that have been considered here present either one property or the other, except for the grass structure which combines evapotranspiration with high inertia.

To properly account for the composite effect of radiative and thermal properties, we propose a for-purpose solar transmission index, noted $\tau$. This proposed index is defined by the following equation and depends on depth $₹$ albedo $\alpha$, emissivity $\varepsilon$ and the thickness $e_{k}$ and conductivity $\lambda_{k}$ of the overlying material layers: 


$$
\tau(z)= \begin{cases}1-\alpha+\varepsilon & \text { for } z=0 \\ (1-\alpha+\varepsilon) \cdot \frac{e_{0} / \lambda_{0}}{\sum_{k} \frac{e_{k}(z)}{\lambda_{k}}} & \text { for } z<0\end{cases}
$$

The reference conductance $e_{0} / \lambda_{0}$ is equal to $1 \mathrm{~W} \cdot \mathrm{m}^{-2} \cdot \mathrm{K}^{-1}$ and is used to render $\tau$ dimensionless. For $z=0, \tau$ is equal to the total flat-line surface absorptivity of the pavement.

Figure 15 illustrates the ratio between the heat flow amplitude $\left(V_{z, \max }-V_{z, \min }\right)$ and surface irradiance $(S+L)$ for each sample 6 and $14 \mathrm{~cm}$ deep as a function of $\tau$. The effective thermal properties presented in Table 6 are used. Alongside these data points, the best least-squares regression linear fit is also plotted with its equation and coefficient of determination.

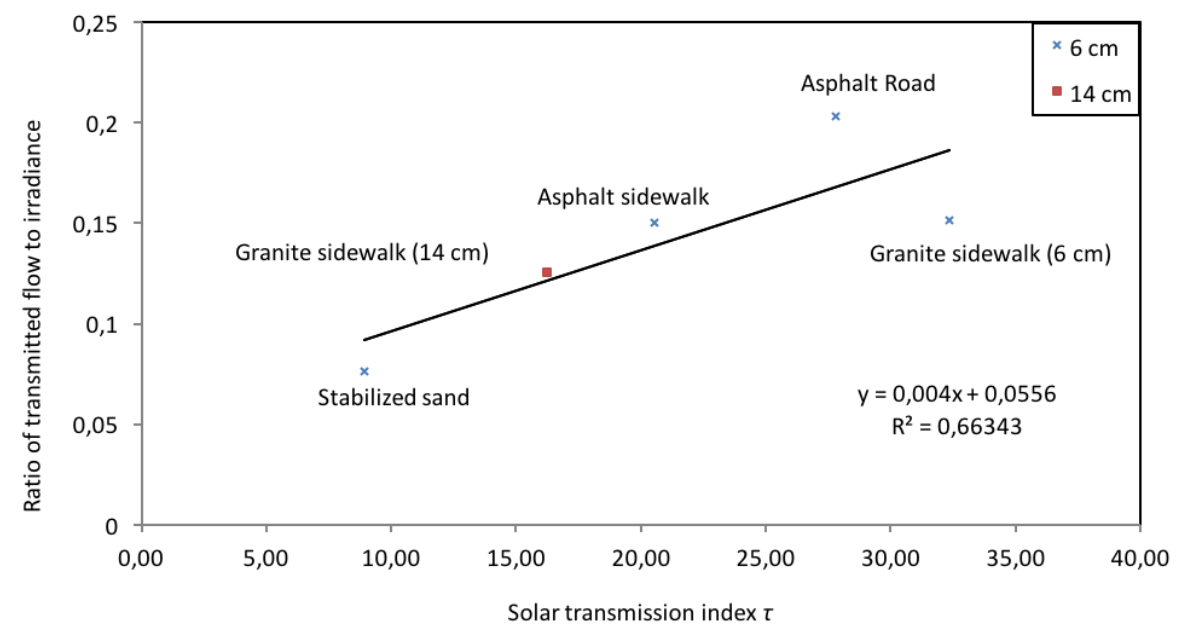

Figure 15 : Ratio of heat flow amplitude to irradiance as a function of $\tau$.

The flow amplitude observed 6 and $14 \mathrm{~cm}$ deep, relative to incident radiation, show good correlation with $\tau$. Thus, for the same incident radiation, the more conductive the surface layers are and the more absorbent the surface, the greater the flow transmitted inside the structure becomes. This is how the granite sidewalk, which is reflective but very conductive, transmits as much heat $6 \mathrm{~cm}$ deep as the asphalt sidewalk.

This solar transmission index merits more case study materials, but could be used as a criterion to select structures according to their ability to transmit incident solar radiation in depth. This may be useful when temperature-sensitive urban infrastructure is present underneath the pavement, such as the local electricity grid.

\section{Conclusion}

A lab experiment was developed to characterize the relative thermal and climatic behavior of five Parisian street structures. $32 \mathrm{~cm}$ tall cylindrical samples were constructed in the lab with the same composition as in the field and instrumented with temperature and heat flow sensors. Sensors were placed at the sample surface and $6 \mathrm{~cm}, 14 \mathrm{~cm}$ and $25 \mathrm{~cm}$ deep. These measurements were used to study thermal behavior, while atmospheric heating by the pavement structures was evaluated on the basis of the surface-air temperature difference. Each sample underwent three consecutive 24-hour test cycles under heat-wave conditions, divided into day and night phases.

Grass was by far the coolest structure at all depths during the day and found to contribute least to atmospheric heating. The stabilized sand and granite sidewalk were second coolest, with the asphalt road and sidewalk structures being the warmest. The granite sidewalk exhibited surprising behavior: cool during the day, but hot at night at its surface, confirmed by its "warm" thermal behavior at greater depths. In addition, the grass and sidewalk structures exhibited the greatest thermal inertia over the three-day test period.

These observations confirm that the experimental setup is able to reproduce the impacts of surface albedo and evapotranspiration as the dominant parameters of the thermal and climatic behavior of pavement 
structures. It also proved useful to identify the role of the thermal properties of the underlying layers of pavement structures. In the case of the granite sidewalk, the combination of high effusivity and diffusivity allow it to exhibit "cool" behavior during the day and "hot" behavior at night despite its relatively high albedo. The asphalt sidewalk shares these properties, though to a lesser extent. This is partly attributed to the presence of their concrete foundation.

While low pavement surface temperatures will help reduce air temperature in cities, high pavement thermal inertia can help slow temperature rises in the event of a heat wave, though its role is limited to only a few degrees at the pavement surface [12]. Among the five structures considered, the grass structure provided the lowest surface temperatures (thanks to evapotranspiration) and highest thermal inertia. Among nonvegetated structures, the granite sidewalk offers the second-best option combining low surface temperature and high inertia, though the stabilized sand structure is the coolest and the asphalt sidewalk offers the highest inertia.

Finally, a solar transmission index was proposed, including both the radiative and the thermal properties of a structure's constitutive layers, to rank structures by their ability to transmit absorbed radiation in depth. High heat transmission can pose risks for temperature-sensitive underground infrastructure such as local electricity grids. This index can help select appropriate overlying materials for such infrastructure.

Following this preliminary work, future tests with this experimental setup will focus on evaluating the behavior of other pavement structures under consideration as potential cool alternatives to the traditional Parisian structures considered here. Further developments will aim to study the effects of pavementwatering of difference structures in order to clarify the technique's effectiveness on other structures than asphalt roads as well as the role of albedo and of the structures' thermal properties on pavement-watering's effectiveness. The watering method will also be fine-tuned in the lab before deployment in the field is tested.

\section{Acknowledgements}

The authors acknowledge the significant support of the Roads and Traffic and the Waste and Water Divisions of the City of Paris for their time, expertise and material support. Funding for this experiment was provided by APUR (Paris Urbanism Agency). The authors would also like to thank Agnès Maitre and Willy Daney de Marcillac at INSP UMR 7588 at Sorbonne Université for permitting the use of their Cary 5 UV-Vis-NIR spectrophotometer and their technical assistance.

\section{References}

[1] T. Asaeda, V. T. Ca, and A. Wake, "Heat storage of pavement and its effect on the lower atmosphere," Atmos. Environ., vol. 30, no. 3, pp. 413-427, Feb. 1996.

[2] M. Santamouris, "Using cool pavements as a mitigation strategy to fight urban heat island-A review of the actual developments," Renew. Sustain. Energy Rev., vol. 26, pp. 224-240, Oct. 2013.

[3] H. Akbari, M. Pomerantz, and H. Taha, "Cool surfaces and shade trees to reduce energy use and improve air quality in urban areas," Sol. Energy, vol. 70, no. 3, pp. 295-310, Jan. 2001.

[4] D. E. Bowler, L. Buyung-Ali, T. M. Knight, and A. S. Pullin, "Urban greening to cool towns and cities: A systematic review of the empirical evidence," Landsc. Urban Plan., vol. 97, no. 3, pp. 147155, Sep. 2010.

[5] T. Kinouchi and M. Kanda, "An Observation on the Climatic Effect of Watering on Paved Roads," J. Hydrosci. Hydraul. Eng., vol. 15, no. 1, pp. 55-64, 1997.

[6] A. Synnefa, M. Santamouris, and H. Akbari, "Estimating the effect of using cool coatings on energy loads and thermal comfort in residential buildings in various climatic conditions," Energy Build., vol. 39, no. 11, pp. 1167-1174, Nov. 2007.

[7] J.-M. Robine et al., "Death toll exceeded 70,000 in Europe during the summer of 2003.," C. R. Biol., vol. 331, no. 2, pp. 171-178, Feb. 2008.

[8] M. Hendel, M. Colombert, Y. Diab, and L. Royon, "Improving a pavement-watering method on the basis of pavement surface temperature measurements," Urban Clim., vol. 10, no. December, pp. 189200, Dec. 2014.

[9] M. Hendel, P. Gutierrez, M. Colombert, Y. Diab, and L. Royon, "Measuring the effects of urban heat island mitigation techniques in the field: Application to the case of pavement-watering in Paris," 
Urban Clim., vol. 16, pp. 43-58, Jun. 2016.

[10] S. Parison, M. Hendel, K. Jurski, and L. Royon, "The Impact of Different Watering Strategies on the Cooling Effects of Pavement-Watering during Heat-Waves," in PLEA 2017 Proceedings - Design to Thrive, 2017, pp. 120-127.

[11] M. Hendel, M. Colombert, Y. Diab, and L. Royon, "An analysis of pavement heat flux to optimize the water efficiency of a pavement-watering method," Appl. Therm. Eng., vol. 78, pp. 658-669, Mar. 2015.

[12] Y. Qin and J. E. Hiller, "Understanding pavement-surface energy balance and its implications on cool pavement development," Energy Build., vol. 85, pp. 389-399, Dec. 2014.

[13] H. Takebayashi and M. Moriyama, "Surface heat budget on green roof and high reflection roof for mitigation of urban heat island," Build. Environ., vol. 42, no. 8, pp. 2971-2979, Aug. 2007.

[14] L. Doulos, M. Santamouris, and I. Livada, "Passive cooling of outdoor urban spaces. The role of materials," Sol. Energy, vol. 77, no. 2, pp. 231-249, Jan. 2004.

[15] K. Anandakumar, "A study on the partition of net radiation into heat fluxes on a dry asphalt surface," Atmos. Environ., vol. 33, no. 24-25, pp. 3911-3918, Oct. 1999.

[16] D. Camuffo and A. Bernardi, "An observational study of heat fluxes and their relationships with net radiation,” Boundary-Layer Meteorol., vol. 23, no. 3, pp. 359-368, Jul. 1982.

[17] T. Ueno and K. Tamaoki, "Thermal Characteristics of Urban Land Cover by Indoor LampIrradiation Experiment," in The Seventh International Conference on Urban Climate, 2009, no. July, pp. 14.

[18] H. Wu, B. Sun, Z. Li, and J. Yu, "Characterizing thermal behaviors of various pavement materials and their thermal impacts on ambient environment," J. Clean. Prod., vol. 172, pp. 1358-1367, 2018.

[19] S. Parison, M. Hendel, K. Jurski, and L. Royon, "Confrontation de trois méthodes de caractérisation thermo-physique de matériaux urbains hétérogènes," in XIIIe Colloque Inter-universitaire FrancoQuébecois, 2017, p. (In French).

[20] N. P. Avdelidis and A. Moropoulou, "Emissivity considerations in building thermography," Energy Build., vol. 35, no. 7, pp. 663-667, 2003.

[21] S. Marinetti and P. G. Cesaratto, "Emissivity estimation for accurate quantitative thermography," NDT E Int., vol. 51, pp. 127-134, 2012.

[22] H. Akbari and H. D. Matthews, "Global cooling updates: Reflective roofs and pavements," Energy Build., vol. 55, pp. 2-6, Dec. 2012.

[23] Y. Qin and H. He, "A new simplified method for measuring the albedo of limited extent targets," Sol. Energy, vol. 157, no. July 2016, pp. 1047-1055, 2017.

[24] M. Taleghani, M. Tenpierik, and A. Van Den Dobbelsteen, "Indoor thermal comfort in urban courtyard block dwellings in the," Build. Environ., vol. 82, pp. 566-579, 2014.

[25] M. K. Howlader, M. H. Rashid, D. Mallick, and T. Haque, "Effects of Aggregate Types on Thermal Properties of Concrete," Eng. Appl. Sci., vol. 7, no. 7, pp. 900-907, 2012.

[26] J. Luca and D. Mrawira, "New Measurement of Thermal Properties of Superpave Asphalt Concrete," J. Mater. Civ. Eng., vol. 17, no. 1, pp. 72-79, Feb. 2005.

[27] Anon, "International Air Transportation Conference, 1977.," 1977.

[28] H. Li, J. Harvey, and a. Kendall, "Field measurement of albedo for different land cover materials and effects on thermal performance," Build. Environ., vol. 59, pp. 536-546, Jan. 2013.

[29] R. Levinson, H. Akbari, and J. C. Reilly, "Cooler tile-roofed buildings with near-infrared-reflective non-white coatings," Build. Environ., vol. 42, no. 7, pp. 2591-2605, Jul. 2007.

[30] M. Pomerantz, B. Pon, H. Akbari, and S.-C. Chang, "The Effect of Pavements Temperatures On Air Temperatures in Large Cities," Lawrence Berkeley Natl. Lab., p. 22, 2000.

[31] M. Pomerantz, H. Akbari, S.-C. Chang, R. Levinson, and B. Pon, "Examples of Cooler Reflective Streets for Urban Heat-Island Mitigation : Portland Cement Concrete and Chip Seals," Lawrence Berkeley Natl. Lab., no. 49283, p. 24, 2003.

[32] P. Rosado, H. Gilbert, M. Pomerantz, B. Mandel, and R. Levinson, "Cool Pavement Demonstration 
and Study," in Third International Conference on Countermeasures to Urban Heat Island, 2014, pp. 815-826.

[33] D. Yinfei, S. Qin, and W. Shengyue, "Highly oriented heat-induced structure of asphalt pavement for reducing pavement temperature," Energy Build., vol. 85, pp. 23-31, Dec. 2014.

[34] D. Yinfei, S. Qin, and W. Shengyue, "Bidirectional heat induced structure of asphalt pavement for reducing pavement temperature," Appl. Therm. Eng., vol. 75, pp. 298-306, Jan. 2015.

[35] D. Yinfei, W. Shengyue, and Z. Jian, "Cooling asphalt pavement by a highly oriented heat conduction structure,” Energy Build., vol. 102, pp. 187-196, Sep. 2015.

[36] Y. Du and S. Wang, "Oriented heat release in asphalt pavement induced by high-thermalconductivity rods," Appl. Therm. Eng., vol. 90, pp. 424-431, Nov. 2015.

[37] M. Hendel and L. Royon, "The effect of pavement-watering on subsurface pavement temperatures," Urban Clim., vol. 14, pp. 650-654, Dec. 2015. 